\title{
Interaction of ordinary Portland cement and Opalinus Clay: dual porosity modelling compared to experimental data
}

\author{
A. Jenni ${ }^{a^{*}}$, T. Gimmi ${ }^{a, b}$, P. Alt-Epping ${ }^{a}$, U. Mäder ${ }^{a}$, V. Cloet ${ }^{c}$ \\ a RWI, Institute of Geological Sciences, University of Bern, Baltzerstrasse 3, $\mathrm{CH}-3012$ Bern, Switzerland \\ (andreas.jenni@geo.unibe.ch, thomas.gimmi@geo.unibe.ch, peter.alt-epping@geo.unibe.ch, \\ urs.maeder@geo.unibe.ch), +41316314531 \\ ${ }^{\mathrm{b}}$ LES, Paul Scherrer Institut, CH-5232 Villigen, Switzerland (thomas.gimmi@psi.ch) \\ ${ }^{c}$ Nagra, CH-5430 Wettingen, Switzerland (veerle.cloet@nagra.ch) \\ corresponding author
}

\begin{abstract}
Interactions between concrete and clays are driven by the strong chemical gradients in pore water and involve mineral reactions in both materials. In the context of a radioactive waste repository, these reactions may influence safetyrelevant clay properties such as swelling pressure, permeability or radionuclide retention.

Interfaces between ordinary Portland cement and Opalinus Clay show weaker, but more extensive chemical disturbance compared to a contact between low-pH cement and Opalinus Clay. As a consequence of chemical reactions porosity changes occur at cement-clay interfaces. These changes are stronger and may lead to complete pore clogging in the case of low-pH cements. The prediction of pore clogging by reactive transport simulations is very sensitive to the magnitude of diffusive solute fluxes, cement clinker chemistry, and phase reaction kinetics. For instance, the consideration of anion-depleted porosity in clays substantially influences overall diffusion and pore clogging at interfaces. A new concept of dual porosity modelling approximating Donnan equilibrium is developed and applied to an ordinary Portland cement - Opalinus Clay interface. The model predictions are compared with data from the cement-clay interaction $(\mathrm{Cl})$ field experiment in the Mt Terri underground rock laboratory (Switzerland), which represent 5 y of interaction.

The main observations such as the decalcification of the cement at the interface, the Mg enrichment in the clay detached from the interface, and the $S$ enrichment in the cement detached from the interface, are qualitatively predicted by the new model approach. The model results reveal multiple coupled processes that create the observed features. The quantitative agreement of modelled and measured data can be improved if uncertainties of key input parameters (tortuosities, reaction kinetics, especially of clay minerals) can be reduced.
\end{abstract}

\section{Keywords}

cement - clay interaction, diffusion, dual porosity, reactive transport modelling, near field, radioactive waste repository

\section{Highlights}

- Diffusion across cement - clay interfaces causes multiple reaction zones.

- New dual porosity transport modelling concept approximates Donnan equilibrium.

- Dual porosity concept questions complete porosity clogging in clays.

- New model approach well describes measured data and reveals underlying processes. 


\section{Introduction}

Many countries consider claystones, such as Opalinus Clay (OPA) in Switzerland or Callovo Oxfordian claystone in France, as ideal host rocks for radioactive waste repositories, because they act as hydraulic and chemical barriers. Designs for geological disposal of radioactive waste foresee cementitious materials as structural elements, backfill or waste encapsulation matrix. Chemical gradients in the pore water at interfaces of contrasting materials, such as concrete in contact with a claystone or compacted bentonite, cause diffusive fluxes of dissolved species across these interfaces and subsequent mineral reactions preferentially at these locations in the barrier system. Such alterations are in turn expected to locally influence properties like permeability, swelling pressure, or specific transport properties. Indirect evidence for porosity clogging at an interface between a low-pH cement and OPA was indicated by substantial mineral precipitation in both materials (Jenni et al., 2014), and a similar thickness of the reaction zones after two consecutive measurements after 2.2 and $4.8 \mathrm{y}$. On the other hand, reaction zones at interfaces between ordinary Portland cement (OPC) and OPA are wider, but less prominent, and possibly still propagating with time. This might indicate that porosity clogging is smaller at OPC interfaces than at low-pH cement interfaces. Unfortunately, no porosity measurements are possibly during in-situ experiments. A new method based on neutron imaging of small laboratory samples (Shafizadeh et al., 2015) may provide additional experimental data in the future.

Reactive transport simulations by Berner et al. (2013) and Kosakowski and Berner (2013) predict substantial porosity changes at interfaces between both OPC - OPA and low-pH cement - OPA. Their reactive transport approach focusses on long-term and large-scale interaction with a minimum node distance of $1 \mathrm{~cm}$. Because most reaction zones observed experimentally in comparable materials over laboratory time-scales (1-10 years) have extents far below $1 \mathrm{~cm}$, a comparison of such modelling results with experimental data, and therefore model verification, is impossible.

The modelling approach of Dauzères et al. (2016) aims at reproducing mineral reactions observed at a 5 y old low-pH cement - OPA interface during the Mt Terri Cl project (Jenni et al., 2014). According to the thickness of the reaction zone, a mesh size of $50 \mu \mathrm{m}$ is chosen. The study focusses on the nature of the Mg hydrate precipitating in the cement, and pore clogging is not discussed, although diffusive transport is coupled with porosity changes in the model. The model predicts no phase transformations on the OPA side, which contradicts experimental observations. Hence in their study model results and experimental data agree only qualitatively.

Accepting the fact that a significant portion of pore water is affected by clay sheet surface charge it appears logical that a model should explicitly account for electrostatic effects and also allow for diffusive transport in this aniondepleted porosity fraction. As detailed below, this is done with a dual porosity concept, assuming equilibrium between the two aqueous phases occupying the two porosities. The equilibrium constraint applied here approximates the Donnan equilibrium resulting from Poisson-Boltzmann theory.

Only few existing transport codes allow for diffusion in pore water affected by the negative clay sheet surface charge: CrunchFlowMC (Steefel, 2009), PhreeqC (Appelo and Wersin, 2007), and an in-house development of Clay Technology AB (Birgersson and Karnland, 2009). These codes define the chemistry of the pore water in terms of Donnan equilibrium between the anion-depleted porosity and the freely accessible porosity, generally assuming equal chemical potential and identical activity coefficients in both porosities, see e.g., Tournassat and Steefel (2015). The new approach presented here is different in that it replaces the explicit Donnan equilibrium formulation with a partitioning between the freely accessible porosity and the anion-depleted porosity based on diffusion/ electromigration. The surface charge (or cation exchange capacity, CEC) of clay minerals is expressed in terms of evenly distributed immobile negative charges. This concept can be implemented in any multicomponent transport code considering the Nernst-Planck equation. Furthermore, it allows for a high flexibility concerning various issues currently under discussion (e.g., activity calculation, speciation and precipitation in the anion-depleted porosity, 
tortuosities in the two porosity domains, connectivity of the different porosities across interfaces, kinetics of cation exchange).

\section{Experimental and data processing methods}

The OPC-OPA interface sample studied here originates from the Mt Terri Cl experiment (Jenni et al., 2014). The OPC, along with other types of concrete, were cast into a vertical borehole. After $4.85 \mathrm{y}$ the interface between concrete and OPA was recovered through an inclined borehole that was backfilled with dummies and resin in the lower part, and cementitious material far away from the experiment. In contrast to overcoring the entire experiment, this technique ensures minimal interference with the remaining material and continued clay-cement interaction. Exposure to air was minimised and water contact was avoided throughout all drilling and sample preparation steps. The sample was embedded in resin, and cutting was done with a diamond saw using petroleum as lubricant. The cut surface was processed using grinding paper, oil-based diamond suspensions and petroleum, resulting in polished sections for the scanning electron microscope (SEM). Details about concrete and OPA composition, experimental setup, sophisticated sampling involving interface stabilisation with glued-in anchors, and sample preparation can be found in Jenni et al. (2014). Please note that the OPC cement composition was wrongly labelled as ESDRED and vice versa in Table 2 of the publication.

The uncoated sample surface was examined in a SEM (Zeiss EVO-50 XVP) equipped with an EDAX Sapphire light element detector in low vacuum mode (10 Pa) with a beam acceleration of $20 \mathrm{kV}$ and a working distance of $8.6 \mathrm{~mm}$. The beam current was adjusted to yield a dead time of 10-20\% for energy dispersive spectroscopy (EDX) analysis. EDX element maps with resolutions of 4-7 $\mu \mathrm{m} /$ pixel were acquired using a dwell time of $300 \mu \mathrm{s}$, repeating 128 or 256 frames. The total measuring area was divided into fields which were reassembled after acquisition. Normalisation of each field to total counts is necessary to compensate for filament weakening, which is significant during the total measurement time of 20-30 h, depending on the size of area of interest. EDX point measurements were acquired for $60 \mathrm{~s}$ live time and semi-quantitatively analysed without standardisation using the EDAX Genesis software (ZAF matrix correction). All detected element fractions heavier than fluorine were normalised to add up to $100 \mathrm{~mol} \%$. Errors are below $3 \mathrm{~mol} \%$ in low-vacuum mode. The skirt effect broadens the beam in low vacuum and leads to an increased measurement volume. However, all measurements in the cement matrix were treated as measurements of phase mixtures, because the grain size of hydrates is expected to be below the measurement volume of approximately 1-2 $\mu \mathrm{m}$ in diameter. Alternatively to point measurements, average EDX spectra of fields of $0.55 \times 0.43 \mathrm{~mm}$ in the OPA have been acquired for $4.1 \mathrm{~min}$ and quantified as described above. 7 fields were measured parallel to the interface, 38 fields perpendicular. The averages of each of the 7 fields can be plotted as a function of the distance from the interface; the range of the 7 fields indicates the chemical variability parallel to the interface. For $\mathrm{Ca}, \mathrm{S}$, or $\mathrm{Fe}$, this range is in general larger than a possible gradient perpendicular to the interface, because large calcitic bioclasts and pyrite nests are heterogeneously distributed in the OPA. In turn, for $\mathrm{Mg}$, differences as small as $2 \mathrm{~mol} \%$ can be detected. Further details of this approach are available in Wersin et al. (2015). In concrete, this approach is not applicable: the large aggregates require fields of measurement much larger than the thicknesses of the chemical heterogeneities, and the latter will not be resolved.

For quantitative comparison of EDX measurements with model results, the essential model output consists of phase volume fractions and solute concentrations at different interaction times. From these data, the grid geometry, and the phase specifications, the absolute content of each element per total volume of the porous media $\left(\mathrm{mol} / \mathrm{m}^{3}\right.$ porous media) was calculated as a function of its distance from the interface. Only the elements of the modelled total chemistry, which were measured by EDX, were then normalised to $100 \mathrm{~mol} \%$. The resulting spatially resolved chemistry was then directly compared with spatially resolved EDX field measurements. To compare model results with 
deliberately chosen EDX points within the cement or clay matrix, the phases avoided such as concrete aggregates, clinkers, calcite (bioclasts), pyrite, or quartz (grains) were excluded from the total chemistry calculation.

\section{Model approach}

The 1D multicomponent reactive transport modelling was performed with the reactive transport code FLOTRAN (Lichtner, 2007). Because advection is considered to be negligible in these types of clay hosted systems, only diffusive transport and electrochemical migration were included in the calculations.

Similar dual porosity reactive transport simulations were performed by using CrunchFlowMC and PhreeqC. Capabilities and comparison of these codes with respect to dual porosity transport are available in Alt-Epping et al. (2014). Results of cement-OPA interface simulations have been reported in Jenni et al. (2015).

\subsection{Modelling cement hydration}

Diffusive exchange and subsequent reactions between concrete and clay rock starts with the unhydrated cement slurry brought in contact with the clay rock. Severe interactions between the materials are likely to occur during the early stage of cement hydration. Therefore, simulations should start with the onset of cement hydration and should not be restricted to the interaction of hardened cement and clay rock.

The aggregate content of the concrete and the cement composition are taken from Jenni et al. (2014), Table 2. The aggregates, a rounded river sediment, consist of quartz and calcite (abundant in the sand fraction), as well as feldspars, sheet silicates, and other metamorphic minerals. Aggregate granulometry: $1066 \mathrm{~kg} / \mathrm{m}^{3}$ sand $0-4 \mathrm{~mm}$, $381 \mathrm{~kg} / \mathrm{m}^{3}$ gravel $4-8 \mathrm{~mm}, 457 \mathrm{~kg} / \mathrm{m}^{3}$ gravel $8-16 \mathrm{~mm}$. The 2.2 y old OPC-OPA interface described therein includes an OPC prepared with $\mathrm{w} / \mathrm{c}=0.35$ (water cement weight ratio). The low $\mathrm{w} / \mathrm{c}$ caused uncommon features such as zones of hindered clinker hydration. Meanwhile, $4.85 \mathrm{y}$ old interfaces containing the same concrete, but with $w / c=0.8$, were measured (Mäder et al., accepted). Therefore, w/c=0.8 was used in the initial conditions of the model in this study. The aggregates were considered as inert and non-porous, but they were included in the initial condition because of their influence on total diffusive transport. The low specific surface areas of the aggregate minerals justify this assumption within the limited time-scale of the model, in contrast to reactive mineral cement additives like nanosilica. $\mathrm{Cl}$ diffusion in concrete is an important issue due to its major role in corrosion of reinforcement, (e.g., Delagrave et al., 1996). More recently self-diffusion of water in cement pastes was investigated by nuclear magnetic resonance (Nestle et al., 2007). The latter found $D_{\text {water }} / D_{\text {o,water }}$ values (self-diffusion coefficient in cement paste/self-diffusion coefficient in free water, comparable with the geometric factor $\mathrm{G}$, equalling constrictivity/tortuosity) of around 0.2 for $w / \mathrm{c}=0.5 \mathrm{OPC}$ pastes of $40 \mathrm{~h}$, around 0.065 at $6 \mathrm{~d}$, or around 0.025 at $81 \mathrm{~d}$. OPC pastes with $\mathrm{w} / \mathrm{c}=0.33$ result in 10 times smaller values. $\mathrm{Cl}$ diffusion measurements at high w/c are scarce: Erdoğdu et al. (2004) report $D_{\text {apparent }}=6.4-12.4 \mathrm{E}-12 \mathrm{~m}^{2} / \mathrm{s}$ for a mature $w / c=0.6$ concrete. Using the simplified effective diffusion-porosity relationship $D_{\text {eff }}=G \cdot n \cdot D_{0}$ with $G=0.1$ (from above) and $n=0.13$ ( $n$ : porosity fraction of 0.13 resulting from modelling undisturbed concrete hydration for a period of $4.85 \mathrm{y}), D_{\text {eff }}(\mathrm{Cl})=2.6 \mathrm{E}-11 \mathrm{~m}^{2} / \mathrm{s}$. Considering higher $\mathrm{w} / \mathrm{c}=0.8$ in the concrete of this study, $\mathrm{G}=0.1$ seems a reasonable choice, probably underestimating $\mathrm{G}$ within the first days of hydration, but overestimating $\mathrm{G}$ in the mature concrete.

Modelling predicts fast hydration of the high periclase content in this cement. But spatially resolved X-ray diffraction $(\mu \mathrm{XRD})$ measurements on $4.85 \mathrm{y}$ old cements reveal remaining unreacted periclase always coexisting with unreacted ferrite. This suggests periclase inclusions within slowly hydrating ferrite produced by processes in the cement kiln. Therefore, the same kinetics used for ferrite hydration were applied to periclase. Comparing the clinker's total chemistry and the composition based on the periclase, ferrite and aluminate content reveals the presence of additional $\mathrm{MgO}, \mathrm{Fe}_{2} \mathrm{O}_{3}, \mathrm{Al}_{2} \mathrm{O}_{3}, \mathrm{Na}_{2} \mathrm{O}$, and $\mathrm{K}_{2} \mathrm{O}$ not covered by the stoichiometric composition based on the pure compounds. The additional oxides were incorporated into the different clinker phases (Taylor, 1997) resulting in the clinker stoichiometries (Table 1). Therefore, the well-known alkali release from hydrating clinkers follows the clinker 
dissolution kinetics. In contrast, alkali incorporation into calcium silica hydrate (C-S-H) or magnesium silica hydrate (M-S-H), as well as Al, was not included in the model (Brew and Glasser, 2005; L'Hôpital et al., 2016).

Table 1 Stoichiometric clinker composition (calculated from Taylor (1997), chemical composition and periclase content of the cement), fitted dissolution rates, and surface areas.

\begin{tabular}{|l|l|l|l|l|l|l|l|l|r|r|r|}
\hline & & $\mathrm{CaO}$ & $\mathrm{SiO}_{2}$ & $\mathrm{Al}_{2} \mathrm{O}_{3}$ & $\mathrm{Fe}_{2} \mathrm{O}_{3}$ & $\mathrm{Na}_{2} \mathrm{O}$ & $\mathrm{MgO}$ & $\mathrm{K}_{2} \mathrm{O}$ & $\begin{array}{c}\text { log rate } \\
\text { constant 1 } \\
{\left[\mathrm{mol} / \mathrm{m}^{2} / \mathrm{s}\right]}\end{array}$ & $\begin{array}{c}\text { log rate } \\
\text { constant 2 } \\
{\left[\mathrm{mol} / \mathrm{m}^{2} / \mathrm{s}\right]}\end{array}$ & $\begin{array}{c}\text { surface area } \\
\text { for 1 and 2 } \\
{\left[\mathrm{m}^{2} / \mathrm{g}\right]}\end{array}$ \\
\hline alite & $\mathrm{C}_{3} \mathrm{~S}$ & 2.900 & 0.950 & 0.040 & 0.000 & 0.010 & 0.060 & 0.000 & -4.89601 & -7.85993 & 0.00319732 \\
\hline belite & $\mathrm{C}_{2} \mathrm{~S}$ & 1.850 & 0.900 & 0.070 & 0.020 & 0.010 & 0.020 & 0.120 & -5.57226 & -8.06963 & 0.00301906 \\
\hline aluminate & $\mathrm{C}_{3} \mathrm{~A}$ & 2.757 & 0.170 & 1.660 & 0.170 & 0.091 & 0.091 & 0.051 & -6.69547 & not used & 0.00329394 \\
\hline ferrite & $\mathrm{C}_{4} \mathrm{AF}$ & 3.940 & 0.340 & 1.440 & 1.800 & 0.000 & 0.170 & 0.040 & -7.73663 & -4.65078 & 0.00267510 \\
\hline
\end{tabular}

The thermodynamic database Cemdata07.2 (Babushkin et al., 1985; Hummel et al., 2002; Lothenbach and Winnefeld, 2006; Matschei et al., 2007; Moeschner et al., 2008; Schmidt et al., 2008; Moeschner et al., 2009) was merged with the EQ3/6 database. At present, the merged database runs only at $\mathrm{T}=25^{\circ} \mathrm{C}$.

Consideration of solid solutions (ss) in FLOTRAN is not straight forward and calculation time consuming. Therefore, all ideal or non-ideal ss proposed in Cemdata07.2 (C-S-H, M-S-H, 2 AFt ss, 2 hydroganet ss, 5 AFm ss, hydrotalcite ss, strätlingite ss) were each discretised into eleven intermediate phases. The logK was calculated according to data from Cemdata07.2 for each phase and added to the database, except for C-S-H (Walker et al., 2007; consistent with Kulik, 2011), and for M-S-H (Nied et al., 2016). Intermediate phases that did not attain saturation during the simulation were excluded from the model in subsequent simulations to improve performance.

The kinetics of cement hydration mainly depends on the dissolution kinetics of clinker phases. The formation of hydrates is often considered to be instantaneous (Parrot and Killoh, 1984; Lothenbach and Winnefeld, 2006). Here we used a rate law based on transition state theory (Lasaga, 1981; Lasaga, 1984) involving a fast rate constant of $10^{-3} \mathrm{~mol} / \mathrm{m}^{3} / \mathrm{s}$ for all cement hydrates, combined with a generic surface area of $0.01 \mathrm{~m}^{2} / \mathrm{g}$. The dissolution kinetics of individual clinker phases is then fitted to the dissolution rates measured on reference samples of the same cement by XRD (Lothenbach and Wieland, 2006; Lothenbach, 2013). In case of alite, belite, and ferrite, two rates are required for each phase to obtain an accurate fit (Table 1). This was implemented by incorporating two reacting versions of the same phase into the model. For potentially forming non-cement hydrates, kinetic parameters were taken from Palandri and Kharaka (2004) and a generic surface area of $0.1 \mathrm{~m}^{2} / \mathrm{g}$ was used.

\subsection{Dual porosity modelling of Opalinus Clay}

Rock composition and pore water chemistry data for the OPA were taken from the compilation in Berner et al. (2013), based on measured and modelled data (Mäder, 2009; Mazurek, 2011; Pearson et al., 2011). Thermodynamic data from EQ3/6 were used, except for chlorite (7Å chamosite), K-feldspar, and albite, which were treated as inert in order to prevent violation of the phase rule (the number of phases has to be limited to the number of primary species, otherwise no phase equilibrium can be achieved in the initial OPA condition). Considering feldspars as inert at high pH is questionable. However, in the cement literature reviewed in Taylor (1997) feldspar reaction is described as negligible. Thermodynamic data exist for smectites consisting of tetrahedral-octahedral-tetrahedral (TOT) layers, interlayer water, and sorbed exchangeable cations. These data cannot be used in a dual porosity approach (see below), because water and cations are treated as separate phase. Therefore, pyrophyllite was used representing the TOT layer of smectite, considered as inert due to the small extent of reaction to be expected within the time-scale of the model. Kinetic rates for all reactive phases are taken from Palandri and Kharaka (2004). Reactive surface areas of the minerals are unknown and commonly used as fitting parameter, resulting in surface areas up to two magnitudes smaller than measured (Savage et al., 2011). Based on this experience, the uncertainties of the Palandri and Kharaka 
(2004) data, and the lack of any experimental evidence for dissolution especially of clays in the Mt Terri Cl samples, a generic surface area of $0.1 \mathrm{~m}^{2} / \mathrm{g}$ was used. Phase composition and pore water chemistry of the clay rock was equilibrated in FLOTRAN, leading to minor modifications in pore water chemistry. The resulting pore water chemistry was then used in the cement-clay interaction model. Previous model runs showed that the inclusion of $\mathrm{pH}$-buffering amphoteric edge sites (mainly expected on smectite) did not significantly influence the mechanisms at a cement-OPA interface, because their limited capacity was overrun by the comparatively large $\mathrm{OH}^{-}$reservoir generated by the cement. Therefore, they were not included in the current approach.

Half of the total porosity in OPA was considered as porosity with excess cations balancing the negative charge of clay sheets (Fig. 1). This porosity is often called anion-depleted (or anion-free, misleadingly) porosity and consists of the water in the clay interlayer plus the water on clay outer particle surfaces (often called diffuse double layer). The chemical composition of this pore water can be calculated by assuming Donnan equilibrium between the aniondepleted porosity and the remaining fraction of the total porosity which is here referred to as freely accessible porosity, free porosity in short. Donnan equilibrium assumes a uniform composition of the pore water in the anion-depleted porosity (Donnan) and equal activity coefficients in both porosities, written for species i as

$$
\mathbf{c}_{\text {Donnan }}^{\mathrm{i}}=\mathbf{c}_{\text {free }}^{\mathrm{i}} \exp \left(\frac{-\mathrm{z}^{\mathrm{i}} \mathrm{F} \psi_{\text {Donnan }}}{\mathrm{RT}}\right),
$$

where $\mathrm{c}$ is the concentration in the two porosity domains [mol/L], $\mathrm{z}$ is the charge number $[-], \mathrm{F}$ is the Faraday constant, $\Psi_{\text {Donnan }}$ is the Donnan potential $[\mathrm{V}], \mathrm{R}$ is the gas constant $[\mathrm{J} / \mathrm{mol} / \mathrm{K}]$, and $\mathrm{T}$ is the temperature $[\mathrm{K}]$. Eq. 1 represents the average pore water composition close to a charged surface derived from the integration of the more rigorous PoissonBoltzmann formulation (Tournassat and Steefel, 2015). Because these formulations do predict a minor content of anions in this porosity, anion-free porosity is not an appropriate term. In the present work, this porosity is called Donnan porosity, in contrast to the free porosity in which the pore water is internally charge-balanced (called free pore water).

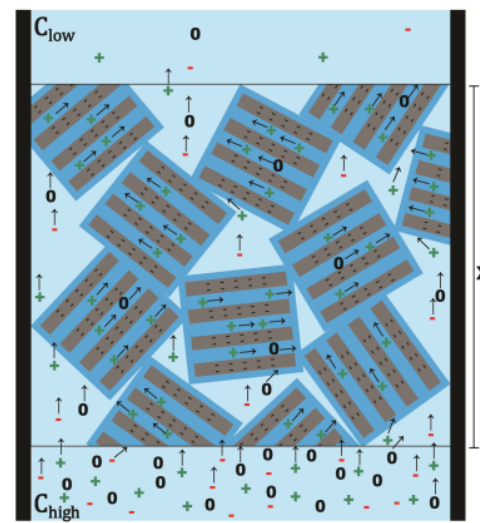

a)

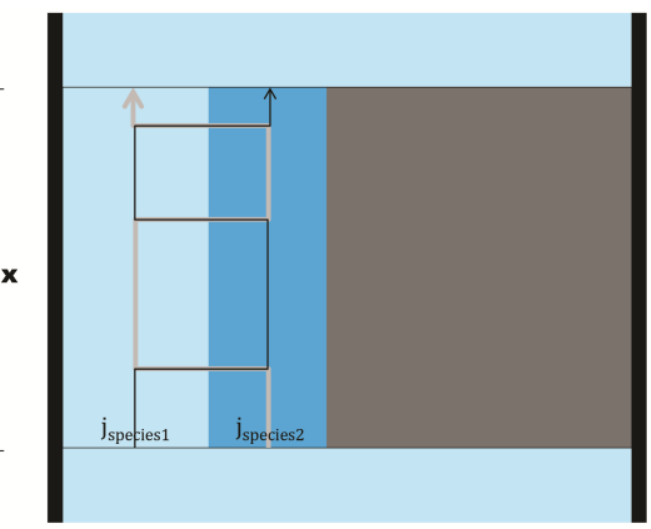

b)

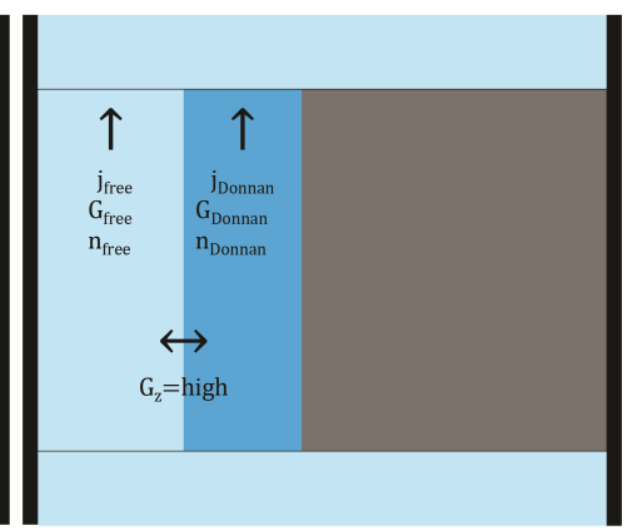

c)

Fig. 1a) Sketch of a monomineralic claystone with free (light blue) and Donnan porosity (dark blue), clay sheets within clay particles in grey. Arrows indicate movements of neutral species (0), cations (+), and anions (-) from a high ionic strength (bottom) to a low ionic strength reservoir (top). b) Diffusion- and electromigration-controlled transport paths of two species. If a species changes from free into Donnan porosity, other species have to compensate for this change following the laws between the two domains. These domain changes are considered as instantaneous. c) In this case, diffusive transport can be treated as two parallel fluxes in two separate porosity domains, which are in diffusive and electrostatic equilibrium. The fluxes $j$ depend on the corresponding geometric factors $G$ and the porosities $n$.

In a Donnan porosity concept, cation exchange can be seen as resulting from Donnan equilibrium between the Donnan porosity and the free porosity, possibly moderated by additional specific sorption. In CrunchflowMC or PhreeqC (Appelo and Wersin, 2007; Steefel, 2009; Tournassat and Appelo, 2011; Alt-Epping et al., 2014; Tournassat and Steefel, 2015), this is implemented by an explicit partitioning function that distributes aqueous species between the two pore compartments. Alternatively, this ion partitioning can be modelled implicitly by diffusion and electrochemical migration (Fick's first law and Nernst-Planck equations) between the free porosity and the Donnan 
porosity, the latter containing immobile anions representing the CEC. The resulting ion compositions of the two equilibrated porosities agree with the concentrations predicted by the Donnan equilibrium, which can be shown in case studies (unpublished results, Gimmi and Alt-Epping). In the present model set-up, this approach was implemented as two connected domains in the $z$ dimension: one containing all minerals plus the free porosity $(z=1)$ and the other containing the Donnan porosity, including the immobile anions (CEC, $z=2$, Fig. 2). Reproducing instantaneous equilibrium between Donnan and free porosities requires a much faster diffusion between the porosity domains than along the porosity domains. This was implemented via an anisotropic geometric factor (G, equal to constrictivity over tortuosity). A kinetic behaviour of (cat)ion exchange could then be implemented simply by decreasing the anisotropy ratio.

In the modelling approach presented here, the Donnan porosity is not associated with a specific clay phase, and the sum of cations in the Donnan porosity represents the bulk CEC of OPA. Consequently, dissolution/precipitation of clay phases do not affect the CEC or the Donnan porosity as they should. However, because the clay phases are virtually stable on the time-scale of the model presented here (rate constant $<10^{-13} \mathrm{~mol} / \mathrm{m}^{2} / \mathrm{s}$ after Palandri and Kharaka, 2004), this assumption is acceptable. Smectite is considered as the phase containing most of the Donnan porosity in its interlayer. Thus it cannot be modelled as $\mathrm{n}\left(\mathrm{H}_{2} \mathrm{O}\right) \mathrm{C}_{x} \mathrm{Si}_{8} \mathrm{Al}_{4-x} \mathrm{Mg}_{\mathrm{x}} \mathrm{O}_{20}(\mathrm{OH})_{4}$, because the water in the interlayer and diffuse layer $\left(n\left(\mathrm{H}_{2} \mathrm{O}\right)\right)$ as well as the CEC cations $\left(\mathrm{C}_{x}\right)$ are part of the Donnan porosity. Therefore, non-reactive pyrophyllite is used as a proxy for the smectite TOT sheets $\left(\mathrm{Si}_{8} \mathrm{Al}_{4-x} \mathrm{Mg}_{\mathrm{x}} \mathrm{O}_{20}(\mathrm{OH})_{4}\right)$.

The calculation of activity coefficients in the Donnan porosity is an additional point of uncertainty. Due to high ionic strengths (5.7 M in pristine OPA), the extended Debye-Hückel formulation is not applicable and a Pitzer approach may be more appropriate. In addition, there is uncertainty as to whether the surface charge needs to be considered in the calculation of activity coefficients. Following the approach taken in CrunchflowMC, activity coefficients in the Donnan porosity were not calculated explicitly but set equal to the activity coefficients calculated for the free porosity. No mineral precipitation is allowed for in the Donnan porosity, which is further discussed in chapter 3.3.

The initial composition in the Donnan porosity is determined in an iterative way by calculating the equilibrium distribution while keeping the initial composition in the free porosity constant. The cations in the Donnan porosity represent now the exchanger population. Computed results generally agree approximately with cation occupancies measured in OPA, as shown before for $\mathrm{Na} / \mathrm{Ca}$ occupancy in montmorillonite (Hedstrom and Karnland, 2011). The above procedure results in an equilibrated OPA system containing a defined mineralogy, the porewater chemistry of the free porosity and that of the Donnan porosity.

The new modelling approach allows for diffusive transport in the free porosity and in the Donnan porosity. Cations in the latter probably contribute to the so-called surface diffusion (Gimmi and Kosakowski, 2011). Theoretically, a fraction of the cations present in the Donnan porosity could be immobilised by surface complexation or conventional ion exchange, mimicking cations in a Stern layer. However, the implementation of a Stern layer is associated with uncertainties of the involved parameters (e.g. distribution factor between Stern layer CEC and Donnan porosity CEC, selectivity coefficients for surface sites).

The geometric factors in the free and Donnan porosities were derived from measured $D_{\text {eff }}$ and accessible porosities for different species (Fig. 1c). It is assumed that the geometric factor in the free porosity is equal for all species present in this domain, and analogously in the Donnan porosity. The $G$ estimation procedure below applies for neutral and tracer species only, where electromigration is insignificant. In contrast, the reactive transport approach applies diffusion and electromigration to all species present.

The dual porosity approach splits the total porosity $n_{\text {total }}$ into free and Donnan porosities, $n_{\text {free }}$ and $n_{\text {Donnan }}$, respectively,

$$
\mathbf{n}_{\text {total }}=\mathbf{n}_{\text {free }}+\mathbf{n}_{\text {Donnan }}
$$

The total diffusive flux $j_{\text {total }}$ of each aqueous species $i$ is then the sum of the fluxes through the free and the Donnan porosity, jiree and jDonnan, respectively. 


$$
\mathbf{j}_{\text {total }}^{\mathrm{i}}=\mathbf{j}_{\text {free }}^{\mathrm{i}}+\mathbf{j}_{\text {Donnan }}^{\mathrm{i}}
$$

It can be written following Fick's first law as

$$
\mathbf{j}_{\text {total }}^{\mathrm{i}}=\mathbf{D}_{\text {eff,free }}^{\mathrm{i}} \frac{\delta \mathrm{c}_{\text {free }}^{\mathrm{i}}}{\delta \mathrm{x}}+\mathbf{D}_{\text {eff,Donnan }}^{\mathrm{i}} \frac{\delta \mathrm{c}_{\text {Donnan }}^{\mathrm{i}}}{\delta \mathrm{x}},
$$

where $D_{\text {eff }}$ is the effective diffusion coefficient in each porosity domain and $\partial \mathrm{C}_{\text {free }} / \partial \mathrm{x}$ is the concentration gradient in the free pore space, and $\partial \mathrm{C}_{\text {Donnan }} / \partial \mathrm{x}$ is the concentration gradient in the Donnan pore space in the $\mathrm{x}$-direction for each species. The two concentrations can be related by $C_{\text {Donnan }}=\beta \cdot C_{\text {free }}$, where $\beta$ is the ratio between the concentration in the Donnan porosity and in the free porosity, which is one for a neutral tracer.

The effective diffusion coefficient for each porosity medium can be written (Flury and Gimmi, 2002) as

$$
\begin{aligned}
& D_{\text {eff,free }}^{i}=G_{\text {free }} n_{\text {free }} D_{0}^{i} \\
& D_{\text {eff,Donnan }}^{i}=G_{\text {Donnan }} n_{\text {Donnan }} D_{0}^{i},
\end{aligned}
$$

where $\mathrm{G}$ is the geometric factor of the free and Donnan porosity, respectively, which is considered to be equal for all species in each domain (note that the distinction of two separate geometric factors, which may be difficult from a conceptual point of view, is a consequence of assuming two parallel fluxes in the dual porosity approach). It follows

$$
\mathbf{j}_{\text {total }}^{\mathrm{i}}=\left(\mathbf{G}_{\text {free }} \mathbf{n}_{\text {free }}+\boldsymbol{\beta}^{i} \mathbf{G}_{\text {Donnan }} \mathbf{n}_{\text {Donnan }}\right) \mathbf{D}_{\mathbf{0}}^{\mathrm{i}} \frac{\delta \mathbf{c}^{\mathrm{i}}}{\delta \mathrm{x}},
$$

where $\mathrm{C}$ instead of $\mathrm{C}_{\text {free }}$ is used from now on. The total effective diffusion coefficient, as experimentally measured, equals for each species:

$$
D_{\text {eff,total }}^{i}=\left(G_{\text {free }} \mathbf{n}_{\text {free }}+\boldsymbol{\beta}^{i} \mathbf{G}_{\text {Donnan }} \mathbf{n}_{\text {Donnan }}\right) \mathbf{D}_{\mathbf{0}}^{\mathrm{i}}
$$

The total geometry factor $\mathrm{G}_{\text {total }}$ represents a weighted average of $\mathrm{G}_{\text {free }}$ and $\mathrm{G}_{\text {Donnan, }}$ according to

$$
\mathbf{G}_{\text {total }} \mathbf{n}_{\text {total }}=\mathbf{G}_{\text {free }} \mathbf{n}_{\text {free }}+\boldsymbol{\beta}^{\boldsymbol{i}} \mathbf{G}_{\text {Donnan }} \mathbf{n}_{\text {Donnan }}
$$

Assuming complete anion exclusion from the Donnan porosity $\left(\beta=0\right.$ and thus $\left.j_{\text {Donnan }}=0\right)$, Eq. 8 reduces to

$$
\mathbf{D}_{\text {eff }, \text { total }}^{\text {anion }}=\left(\mathbf{G}_{\text {free }} \mathbf{n}_{\text {free }}\right) \mathbf{D}_{\mathbf{0}}^{\text {anion }}
$$

$G_{\text {free }}$ and $G_{\text {Donnan }}$ can then be calculated from Eqs. 8 and 10 with $D_{\text {eff }}$ and $n$ values for HTO $(\beta=1)$ and for tracer $\mathrm{I}^{-}(\beta=$ 0) from Pearson et al. (2003) (Table 2). These estimation procedures are based on the idea that $G_{\text {total }}$ derived for a tracer anion is also valid for diffusion of HTO or a cation just within the free pore water.

Table $2 D_{\text {eff }}$ and porosity values from Pearson et al. (2003), calculated $G_{\text {free }}, G_{\text {Donnan , and }} G_{\text {total }}$ compared with $G_{\text {total }}$ from Van Loon et al. (2003), Van Loon et al. (2004), and Gimmi and Kosakowski (2011)for Mont Terri samples perpendicular to bedding.

\begin{tabular}{|l|c|c|c|r|r|r|r|r|}
\hline Species & $\begin{array}{c}\mathrm{D}_{0} \\
{\left[\mathrm{~m}^{2} / \mathrm{s}\right]}\end{array}$ & $\begin{array}{c}\mathrm{D}_{\text {eff }} \\
{\left[\mathrm{m}^{2} / \mathrm{s}\right]}\end{array}$ & $\begin{array}{c}\mathrm{n}_{\text {free }} \\
{[\mathrm{vol} \text { frac }]}\end{array}$ & $\begin{array}{c}\mathrm{n}_{\text {Donnan }} \\
{[\mathrm{vol} \text { frac }]}\end{array}$ & $\begin{array}{c}\mathrm{G}_{\text {free }} \\
{[-]}\end{array}$ & $\begin{array}{c}\mathrm{G}_{\text {Donnan }} \\
{[-]}\end{array}$ & $\begin{array}{c}\mathrm{G}_{\text {total }} \\
{[-]}\end{array}$ & $\begin{array}{c}\mathrm{G}_{\text {total }} \\
{[-]}\end{array}$ \\
\hline \multicolumn{8}{|c|}{ from literature } \\
\hline $\mathrm{HTO}$ & $2.30 \mathrm{E}-09$ & $1.20 \mathrm{E}-11$ & 0.06 & 0.06 & 0.023 & 0.064 & 0.044 & $0.036-0.071$ \\
\hline $\mathrm{I}$ & $2.05 \mathrm{E}-09$ & $2.80 \mathrm{E}-12$ & 0.06 & 0.06 & 0.023 & & 0.023 & $0.022-0.057$ \\
\hline
\end{tabular}

Resulting $G_{\text {free }}$ obtained here for $I^{-}$are consistent with other $G$ values reported for anions in the literature (Van Loon et al., 2003; Van Loon et al., 2004), and was used for all simulations of this study. $G_{\text {Donnan }}$ is higher than $G_{\text {free }}$ (Table 2), which implies that diffusion in the Donnan porosity is faster than in the free porosity. This might be explained by less tortuous ion diffusion paths in the interlayer, compared to the free porosity. More likely, however, it just demonstrates that $G_{\text {free }}$ obtained for an anion (which can only access the free porosity) may be too small for HTO or Na (which can access both porosities and thus can circumvent obstacles for anions via the Donnan porosity). Also, lower diffusivities in the Donnan porosity are likely to occur in highly compacted clays because of space restrictions in thin interlayers, as shown for instance by neutron scattering (factor of 2 for interlayer water, Gonzalez Sanchez et al., 2008; Gonzalez Sanchez et al., 2009). Simulations were run with a low Donnan diffusivity $\left(G_{\text {Donnan }}=0.006\right)$ as well as the value from Table 2. As described above and illustrated in Fig. 1, $G_{\text {free }}$ and $G_{\text {Donnan }}$ were used for calculating diffusive transport of all species in the free and the Donnan porosity. In contrast to the assumptions necessary for the 
estimation of the geometric factors, the model approach predicts minor amounts of anions in the Donnan porosity, consistent with the Donnan equation. Therefore, the model also predicts anion transport in the Donnan porosity, which is calculated with the same $G_{\text {Donnan }}$ used for cation and neutral species diffusion.

One important issue of modelling material interfaces is the fact that the connectivity of free and Donnan porosity across material interfaces is unknown. This uncertainty concerns especially interfaces involving clay and single porosity materials such as filters, or materials with a high porosity contrast. This issue has been discussed recently by Tournassat and Steefel (2015). However, there is no universal solution of this issue valid for any dual-porosity transport medium. The detailed mixing conditions depend on specific pore-scale features that cannot be addressed generically in a continuum-scale model. In the approach presented here the connectivity is defined by the explicit (quasi pore scale) 2D spatial arrangement of free and Donnan porosity in the model as given by the interfaces of two adjacent porosity domains located in $z=1$ and $z=2$ and their cross-sectional areas (Fig. 2). Because the concrete exhibits a single porosity without a mineral surface charge, the two domains $z=1$ and $z=2$ are equal. The fast diffusion between the two domains (in $z$ direction) ensures uniform pore water and phase distribution during the model calculation. In contrast, on the OPA side, free porosity and all OPA mineral phases are located in the $z=1$ domain, and the Donnan porosity is located in the $z=2$ domain; the remaining volume in $z=2$ is occupied with inert material (Fig. 2). From this set-up follows that the OPA free porosity connects with half of the concrete porosity, and the OPA Donnan porosity connects with the other half of the concrete porosity, supported by the fact that the free porosity volume equals the Donnan porosity volume. Variation of the cross-sectional areas of the porosity domains and/or the inert fraction in $z=2$ can generate any other desired connectivity.

Harmonic averaging is applied for diffusion between cells in the main transport direction, i.e. within each porosity domain in $x$ direction in Fig. 2 (Lichtner, 2007). The concentration averaging procedure in the electromigration term as implemented in FLOTRAN was adapted to ensure consistency with the Donnan calculation. The default implementation of an arithmetic mean of neighbouring concentrations (as it is typically implemented in multicomponent transport codes including electromigration) leads to major errors under certain conditions.

In principal, the dual porosity approach presented here can be used to model transport in any material showing anion exclusion. High-density bentonites contain only small free porosity fractions, which can be represented by a small porosity fraction in the $z=2$ domain. In contrast to an explicit formulation of Donnan equilibrium, simulations with the dual porosity approach seem to be numerically more robust. The new model approach can of course also handle conditions in which the entire porosity is made up of Donnan porosity (Birgersson and Karnland, 2009), simply by omitting the $\mathrm{z}=2$ domain and treating the $\mathrm{z}=1$ porosity as Donnan porosity. Implementation of osmotically controlled partitioning between the porosity domains representing changes in interlayer distances in the clay phase is planned, and a coupling of chemical and mechanical parameters is under discussion. 


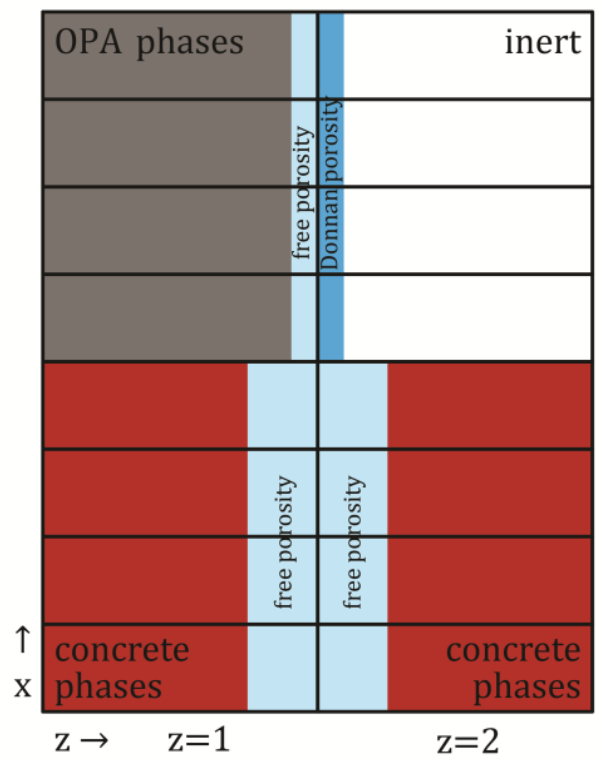

Fig. 2 1D reactive transport ( $x$ direction) model set-up for a concrete-OPA interface with free and Donnan porosity in the OPA (not to scale). Fast diffusive exchange between the porosity domains in the concrete in z-direction ensures that local chemical conditions are uniform. Fast diffusion in z-direction is also a requirement for instantaneous equilibrium conditions between both OPA porosity domains (Donnan equilibrium).

\subsection{Relevance of the dual porosity approach}

Pore clogging due to mineral precipitation can occur in the free porosity, but rarely in the Donnan porosity. Consequently, clogging drastically decreases the diffusion of anions, whereas the diffusion of neutral species or cations is less affected because they can still diffuse through the Donnan porosity. The lab experiment of Chagneau et al. (2015) shows complete inhibition of $\mathrm{Cl}^{-}$tracer diffusion in a compacted illite following celestite precipitation, but HTO diffusion only slowed down by a factor of 0.5. Melkior et al. (2004) measured decreasing anion diffusivity in bentonite and Bure mudrock (Callovo-Oxfordian layer, comparable to OPA) after cement-related pore clogging.

Mineral precipitation might influence anion diffusion in OPA even stronger than in illite: the anion-accessible free porosity fraction in OPA is lower compared to that of compacted illite. However, a higher Donnan/free porosity ratio generally increases the anion content in the Donnan porosity, as predicted by the Donnan equilibrium. Consequently, anion diffusion will not stop even after complete plugging of free porosity. A simplified system using the model approach described above shall demonstrate the importance of the Donnan porosity in a claystone in contact with a single porosity material (e.g., filter, sandstone, concrete), where clogging already occurred at the interface. Initially, a cell with fully clogged free porosity is situated in a claystone right at the interface towards the concrete. Fig. 3 illustrates the discretisation of such a model set-up. The single porosity material (concrete proxy) had a porosity of

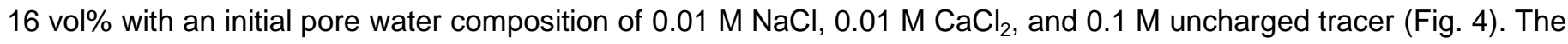
claystone (which was used as OPA proxy) on the opposite side of the clogged interface had a free porosity of $6.4 \%$ with an initial pore water composition of $0.21 \mathrm{M} \mathrm{NaCl}$ and $0.02 \mathrm{M}$ tracer and a Donnan porosity of $6.4 \%$ with an initial pore water composition $4.32 \mathrm{M} \mathrm{Na}^{+}$(exchangeable cations), $0.01 \mathrm{M} \mathrm{Cl}^{-}$, and $0.01 \mathrm{M}$ tracer. The pore waters in both porosity domains were in Donnan equilibrium except for the tracer. The free porosity in the clogged cell was assumed to be $1 \mathrm{E}-6$ with $\mathrm{G}_{\text {tree }}=1 \mathrm{E}-30$ such that diffusion through the free porosity is negligible. Elsewhere in the OPA proxy,

$\mathrm{G}_{\text {free }}=0.023$ and $\mathrm{G}_{\text {Donnan }}=0.064$ were used. In the concrete proxy, $\mathrm{G}_{\text {free }}=0.01$. The domain was discretised in 50 cells of $1 \mathrm{~mm}$ in $\mathrm{x}$ direction and two cells of equal length in $z$ direction (representing Donnan and free porosity in the clay), with no-flux boundaries at both ends. All solids were inert, speciation calculations were limited to $\mathrm{Ca}^{++}, \mathrm{Na}^{+}, \mathrm{Cl}^{-}$, and the neutral tracer. 


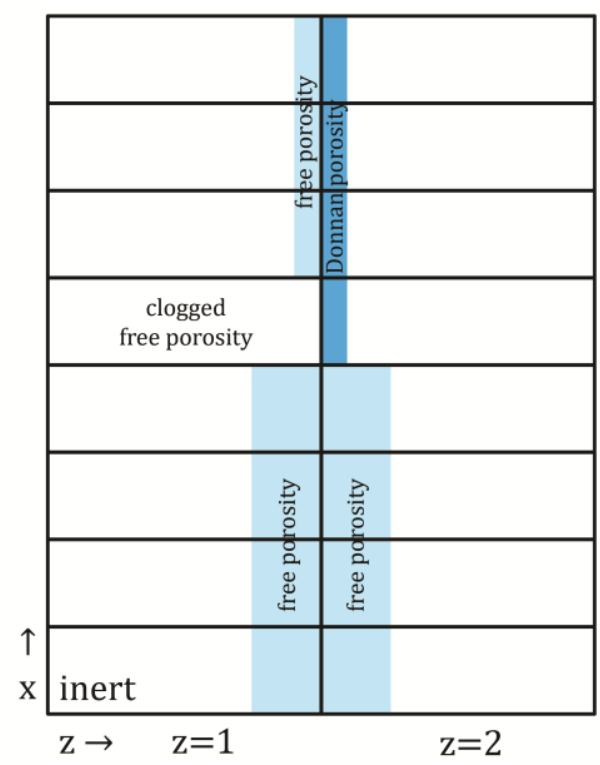

Fig. 3 Model set-up (transport in $x$ direction) for a concrete proxy (bottom)-OPA proxy (top) interface with clogged free porosity in the OPA (not to scale). Fast diffusion in the z-direction ensures uniform local pore water composition in the concrete, as well as Donnan equilibrium between both OPA porosities.

The pore water compositions after $2.4 \mathrm{~h}$ shown in Fig. 4 illustrate that the neutral tracer concentrations in both OPA porosities have fully equilibrated: both Donnan and free porosity show a concentration of $0.015 \mathrm{M}$, except at the interface, where the concentration rises due to the tracer influx from the concrete. Despite the completely plugged free porosity in the OPA at the interface, considerable fluxes evolve across the interface. The $\mathrm{Na}+$ flux from the OPA into the concrete is almost 5 times higher than the $\mathrm{Cl}^{-}$flux after $2.4 \mathrm{~h}$ of interaction. $\mathrm{Ca}^{++}$diffuses into the opposite direction such that charge balance is maintained. This means that almost $80 \mathrm{eq} \%$ of the cations migrate without associated anions such that cations are just exchanged across the interface between the concrete and OPA. Diffusion, electromigration, and the CEC charge in the Donnan porosity are responsible for this process. Over time, species fluxes decrease as gradients across the interface are levelled out.

The limited $\mathrm{Ca}^{++}$pool in the concrete proxy pore water is distributed throughout all porosities leading to the decalcification of the cement. The main $\mathrm{Ca}^{++}$sink is the Donnan porosity in the OPA, which is still $\mathrm{Na}^{+}$dominated due to the comparably large $\mathrm{Na}^{+}$reservoir (large $\mathrm{CEC}$ ). In a system involving reactive minerals the decalcification is more prominent due to cement dissolution and calcite precipitation in the OPA.

The ionic strength contrast between concrete and OPA evens out due to $\mathrm{Na}^{+}$and $\mathrm{Cl}^{-}$diffusion from OPA's free porosity into the concrete via the Donnan porosity of the first concrete cell at the interface (free porosity is clogged). Although the $\mathrm{Cl}^{-}$flux is limited by its low concentration in the Donnan porosity, it becomes comparable to the $\mathrm{Na}^{+}$flux when the initial steep $\mathrm{Na}^{+}-\mathrm{Ca}^{++}$gradients have somewhat evened out (e.g., after $100 \mathrm{~d}$ ). After years of interaction, concentrations in the free porosities are identical on both sides of the interface. The $\mathrm{Ca}^{++}$content in OPA's Donnan porosity (exchanger occupancy) has increased, but is still low compared to the $\mathrm{Na}^{+}$. 


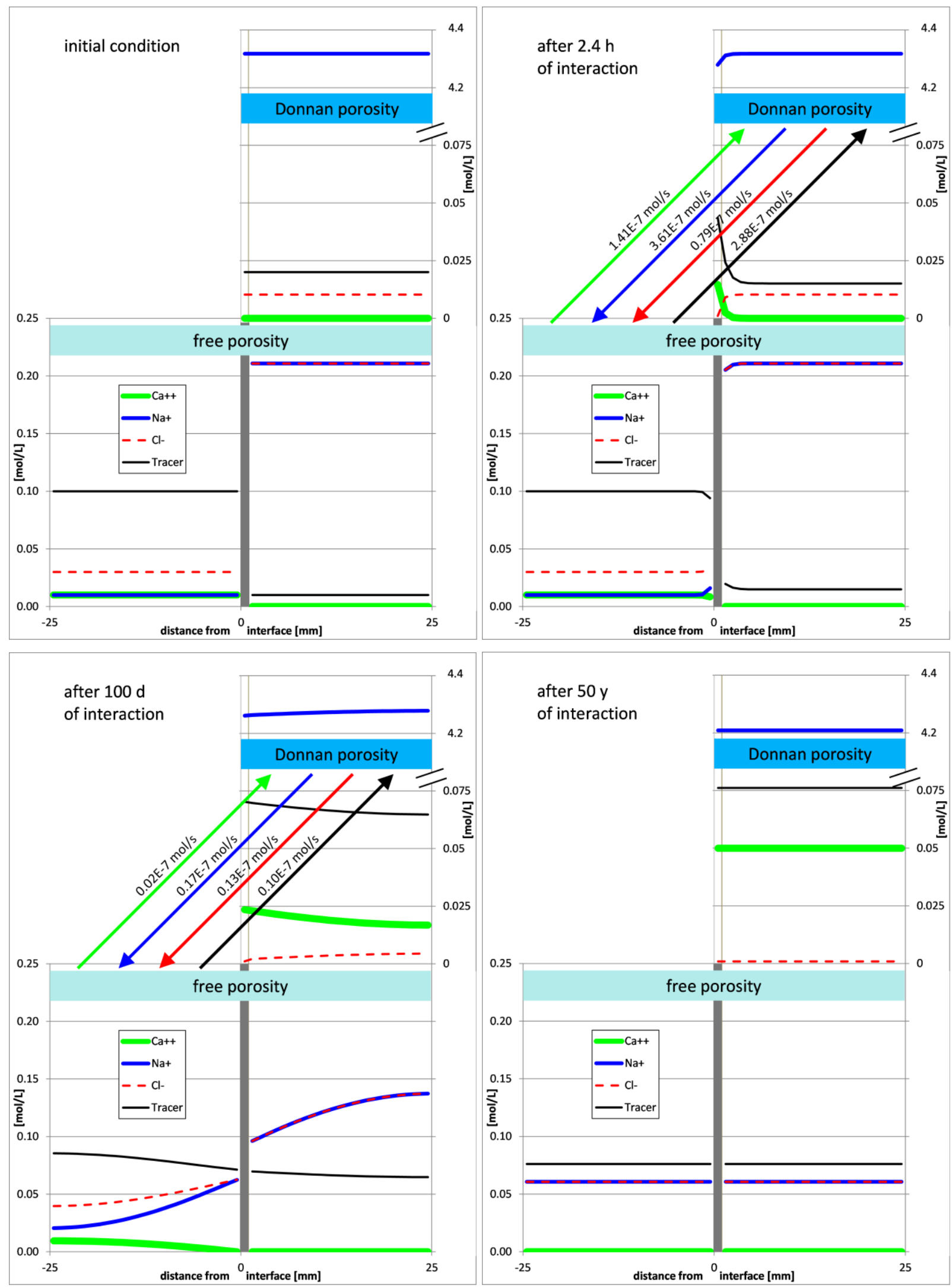

Fig. 4 Species concentrations in the free and Donnan porosities of the concrete (left of interface) and OPA proxy (right of interface) after different interaction times. The interface is at $0 \mathrm{~mm}$. The grey bar to the right of the interface shows the cell exhibiting a clogged free porosity, the arrows indicate the flux of selected species across the interface at the given time. Diffusion across the interface occurs via the connection between the free porosity of the concrete and the Donnan porosity of the OPA.

This simplified set-up clearly demonstrates what happens when solute exchange across an interface can only occur through the Donnan porosity. The $\mathrm{Na}^{+}$flux from OPA into concrete is mainly charge balanced by a $\mathrm{Ca}^{++}$flux in the opposite direction, accompanied by a minor $\mathrm{Cl}^{-}$flux only. This process would be difficult to model with a single porosity approach (although it may be possible to simulate a similar effect by strongly decreasing anion diffusivities using a 
multicomponent transport model including Nernst-Planck equations). Transport in the Donnan porosity is also of great importance in systems with high fractions of Donnan porosity, e.g. in bentonites.

\section{Modelling results}

Initially, the OPC contains pure water within the free porosity, strongly undersaturated with respect to the clinker phases (Fig. 5). The pore water in the OPA free porosity is in chemical equilibrium with the reactive OPA phases as well as in Donnan equilibrium with the Donnan porosity. This initial condition represents the fresh concrete cast into the borehole at the start of the $\mathrm{Mt} \mathrm{Terri} \mathrm{Cl}$ experiment or a shotcrete just applied to the tunnel wall for stabilisation within the repository.

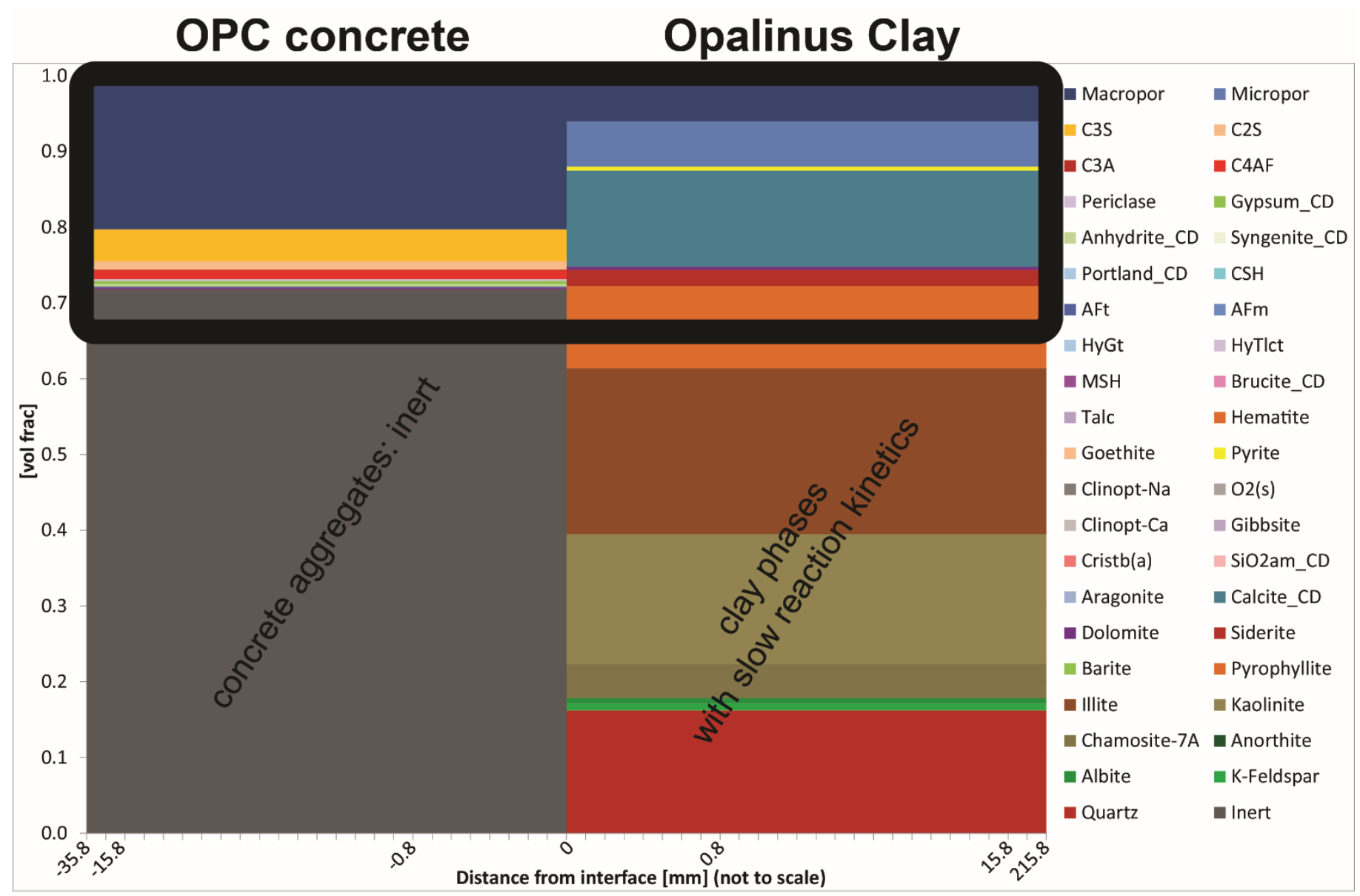

Fig. 5 Initial condition of the concrete - OPA interface. Because concrete aggregates are treated as inert, and many OPA phases show minimal reaction within the timescale of his study, reactive phases only are shown in subsequent figures (top 30 vol\%, black frame). All phases considered are listed on the right, "Macropor" represents free, "Micropor" Donnan porosity. The domain is discretised into $16100 \mu \mathrm{m}$ cells close to the interface, $301 \mathrm{~mm}$ cells further away, and two large cells at the concrete and OPA boundaries.

The cement hydration includes clinker dissolution and precipitation of hydration products. The ensuing porosity reduction is consistent with measured porosity data (Lothenbach and Wieland, 2006). Results show that after $1 \mathrm{~d}$, approximately half of the clinker has dissolved, leading to the precipitation of $\mathrm{C}-\mathrm{S}-\mathrm{H}$, portlandite, ettringite, and an unusual high fraction of hydrotalcite (due to clinker high in Mg) (Fig. 6). At the contact to the OPA, the formation of ettringite and portlandite is reduced later on, and the formation and subsequent disappearance of M-S-H can be observed. The model predicts no $\mathrm{pH}$ reduction in the cement close to the interface. This contradicts the common assumption that the low portlandite and ettringite content observed at such interfaces is caused by $\mathrm{pH}$ values below the stability range of these hydration products. Instead, the modelling results suggest $\mathrm{Ca}^{++}$diffusion into the OPA followed by a lower $\mathrm{Ca}^{++}$availability as a limiting factor for the formation of ettringite and portlandite. 
Dolomite is replaced by calcite throughout the entire cement domain. Carbonation caused by the in-diffusion of carbon species is very limited and only predicted within the first $0.1 \mathrm{~mm}$ from the interface during one month. Within the first days of hydration, iron is incorporated in hydrotalcite and ettringite. Later on, Al-richer solid solutions dominate and minor fractions of goethite precipitate uniformly throughout the cement. Close to the OPA, the model also predicts the formation of pyrite due to the ingress of sulphate and iron. After $2.7 \mathrm{y}$ of interaction (Fig. 7, left), only a minor fraction of clinker remains and M-S-H at the interface is replaced by brucite. From now on only minor changes occur.

A high-pH front rapidly enters the OPA. This front is accompanied by dolomite dissolution and the precipitation of calcite, hydrotalcite, and brucite. Precipitation of calcite and hydrotalcite was also observed in an OPA core infiltrated with a high-pH K-Na-Ca solution, and dolomite dissolution was predicted by the modelling results of the same study (Adler, 2001). After $5 \mathrm{y}$, the model here predicts a zone extending about $16 \mathrm{~mm}$ into the OPA in which the pH exceeds 12.5 and dolomite is completely dissolved. Limited pyrite oxidation caused by oxygen entering from the cement pore water causes a small flux of sulphate back into the concrete. Other phase transformations in the OPA are small: 0.014 vol\% of illite and 0.005 vol\% of kaolinite have dissolved within the high-pH plume over a period of $5 \mathrm{y}$. But these small volumes release $\mathrm{Al}$, which might contribute to hydrotalcite formation in addition to the Al flux entering from the cement. 

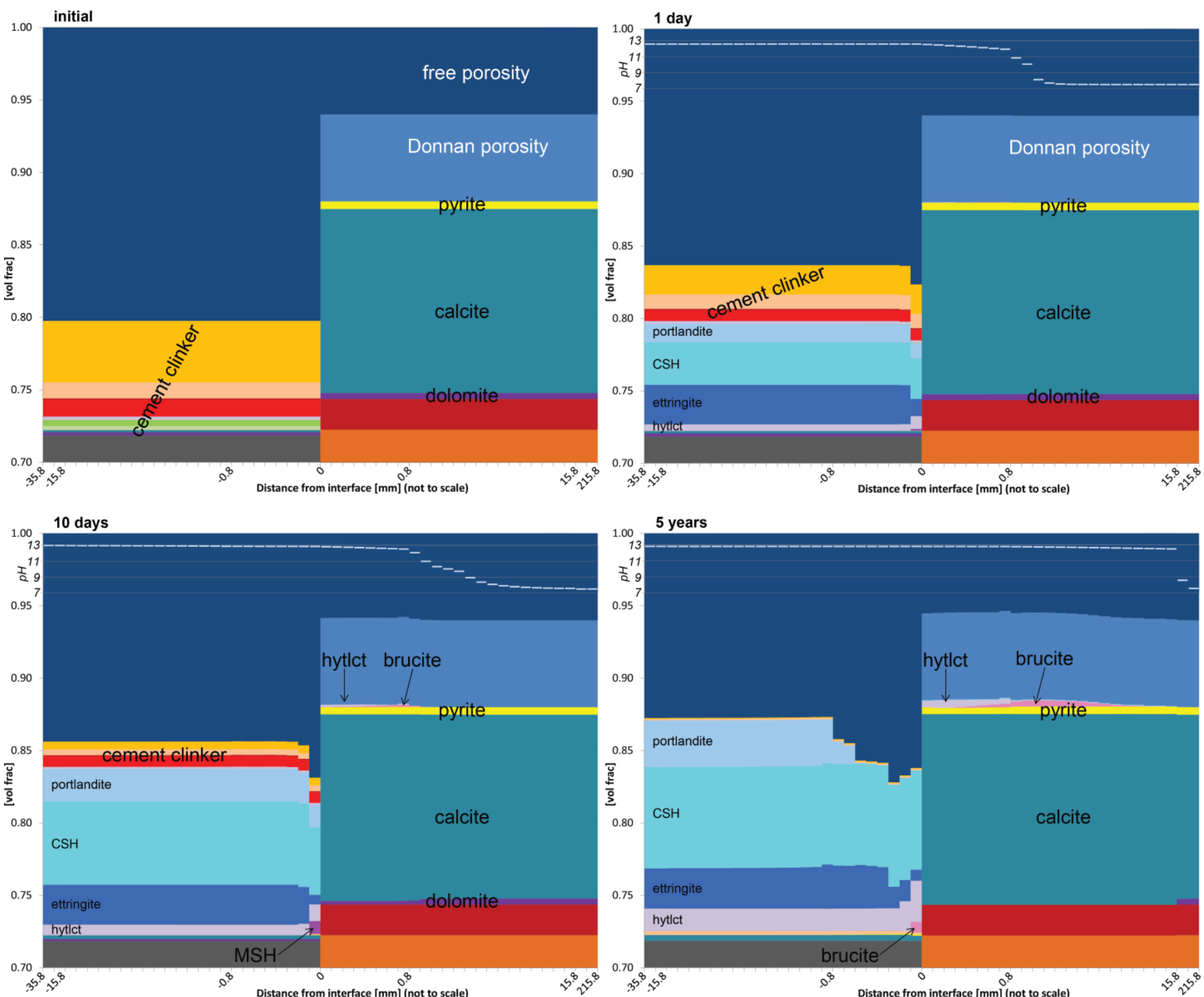

Fig. 6 Initial condition of reactive phases (zoom of Fig. 5), followed by the phase volume fractions after $1 \mathrm{~d}, 10 \mathrm{~d}$, and $5 \mathrm{y}$. $\mathrm{G}_{\mathrm{Donnan}}=0.006$, all other parameters used are explained in chapter 3 . See Fig. 5 for colour legend and further explanations. The white graph indicates the pH in the free pore water (superimposed axis on the left).
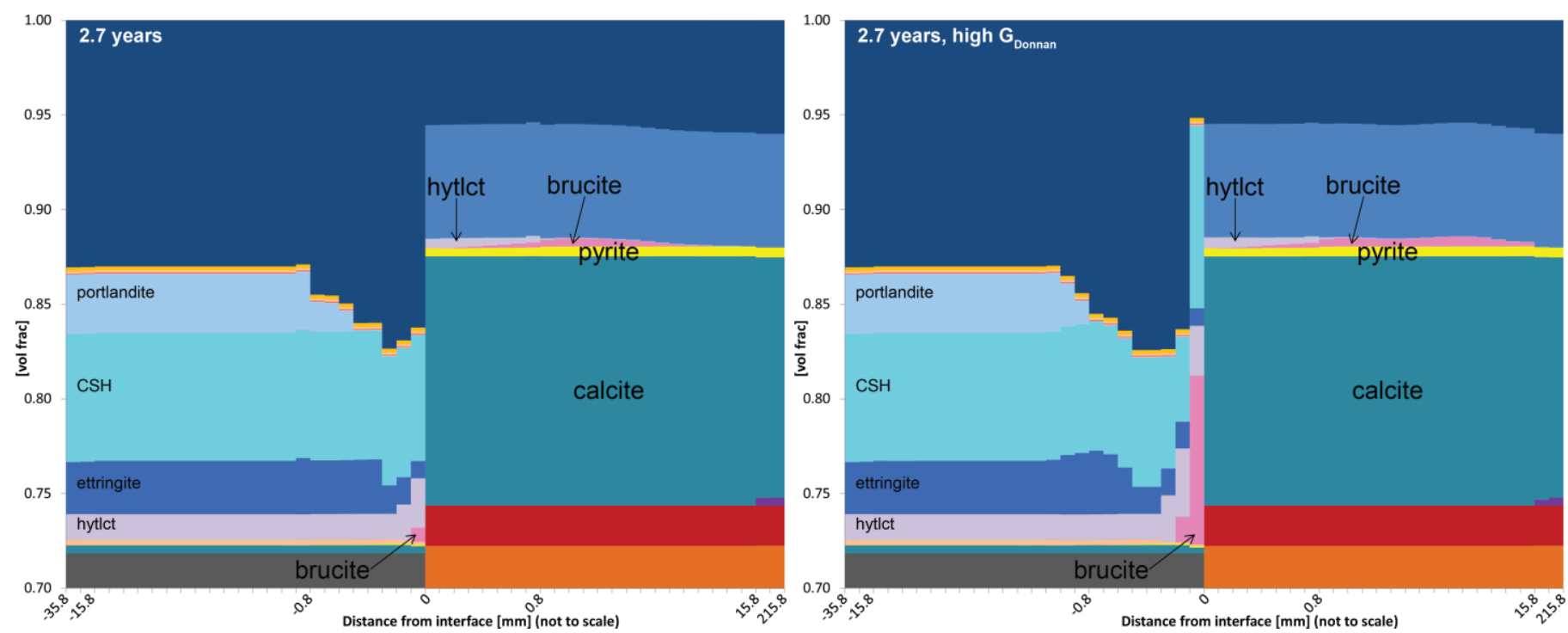

Fig. 7 Comparison of volume fractions after 2.7 y calculated using $G_{\text {Donnan }}=0.006$ as in Fig. 6 (left panel) with a scenario involving faster Donnan diffusion ( $G_{\text {Donnan }}=0.064$ ) (right panel). See Fig. 5 for colour legend and further explanations. 
The clogging of the interface depends on the relationship between diffusion of the individual species and phase precipitation kinetics. In the model set-up presented in Fig. 6, only a small fraction of the free porosity has been clogged $(0.64$ vol\% after $5 \mathrm{y}$ of initially 6 vol\%). One reason for this is that the zone of most intense mineral precipitation is situated within the OPA rather than the concrete, and moves into the OPA with progressing reaction. This zone consists of a combination of hydrotalcite, brucite, and C-S-H (barely visible in the graphs of Fig. 6). Interestingly, the model predicts an intermediate state around $3 \mathrm{~d}$ with gypsum precipitation and subsequent redissolution within the cement and within the OPA at the interface (not shown in Fig. 6). To assess the implication of higher diffusivities in the Donnan porosity we run an additional scenario in which the diffusion in the OPA Donnan porosity is increased to $G_{\text {Donnan }}=0.064$ as suggested in Table 2 . The resulting phase volume fractions after 2.7 y are compared with the base case in Fig. 6. Increasing diffusivities in the Donnan porosity accelerates cation transport within the OPA and leads to significant brucite precipitation in the cement right at the interface due to a $\mathrm{Mg}^{++}$flux from the OPA into the cement. The resulting Mg enrichment in OPC at the interface has not been experimentally observed (see next chapter).

\section{Comparison of modelling results with experimental data after 5 years of interaction}

The numerical results from the model output $\left(G_{\text {Donnan }}=0.006\right)$ were converted into mol fractions per total volume (chapter 2), which can then be compared quantitatively to SEM EDX measurements. Furthermore, the general spatial trends in elemental distributions calculated from modelled data are compared qualitatively with SEM EDX elemental maps.

Although the cement matrix appears to be locally homogeneous in qualitative elemental maps, each spot measures a volume of 1-2 $\mu \mathrm{m}$ in diameter, which contains a variable fraction of submicron cement hydrates. This leads to the large scattering depicted in the graphs in Fig. 8-Fig. 10 and elsewhere (Jenni et al., 2014; Dauzères et al., 2016). EDX involving larger averaged areas would be an alternative if the inhomogeneity of the initial material perpendicular to the expected chemical gradient (e.g., parallel to the interface) is smaller than the gradient itself (chapter 2). This is the case for certain elements in OPA.

The EDX spot measurements in the cement matrix indicate a gentle Ca decrease from 5 to $0.5 \mathrm{~mm}$ from the interface, followed by a steeper decrease closer to OPA (small dots in Fig. 8). The model (orange line) predicts a similar Ca distribution, but within the first 1-2 mm from the interface. The measured $\mathrm{Ca}$ fractions are substantially shifted relative to both the model and the Ca fraction calculated from cement composition (large dot). The shift is interpreted as an artefact of the standard-less semi-quantitative EDX processing, mainly affecting the $\mathrm{Ca} / \mathrm{Si}$ ratio. A slight shift is also observed on the OPA side. However, the Ca map shows a decalcification of the cement matrix close to the interface, which agrees well with the model prediction.

Area measurements of $\mathrm{Ca}$ fractions in the OPA show considerable inhomogeneities parallel to the interface due to the occurrence of large calcitic bioclasts, especially close to the interface (clasts visible in the Ca map, causing the large bars in the graph in Fig. 8). The model predicts a uniform slight increase in Ca within the first $15-20 \mathrm{~mm}$ from the interface (too small to be visible in the graph), which accommodates the $\mathrm{Ca}$ from the decalcification of the cement. The increase predicted by the model is far below EDX sensitivity, and no significant Ca enrichment is seen in the measured data, even though a slight trend to larger values close to the interface appears in the EDX measurements. Note that some samples show cracks in the OPA close to the interface (presumably from initial drilling), which are then filled with calcite after concrete casting. This process is not included in the model, and such veins are avoided during EDX measurements. 


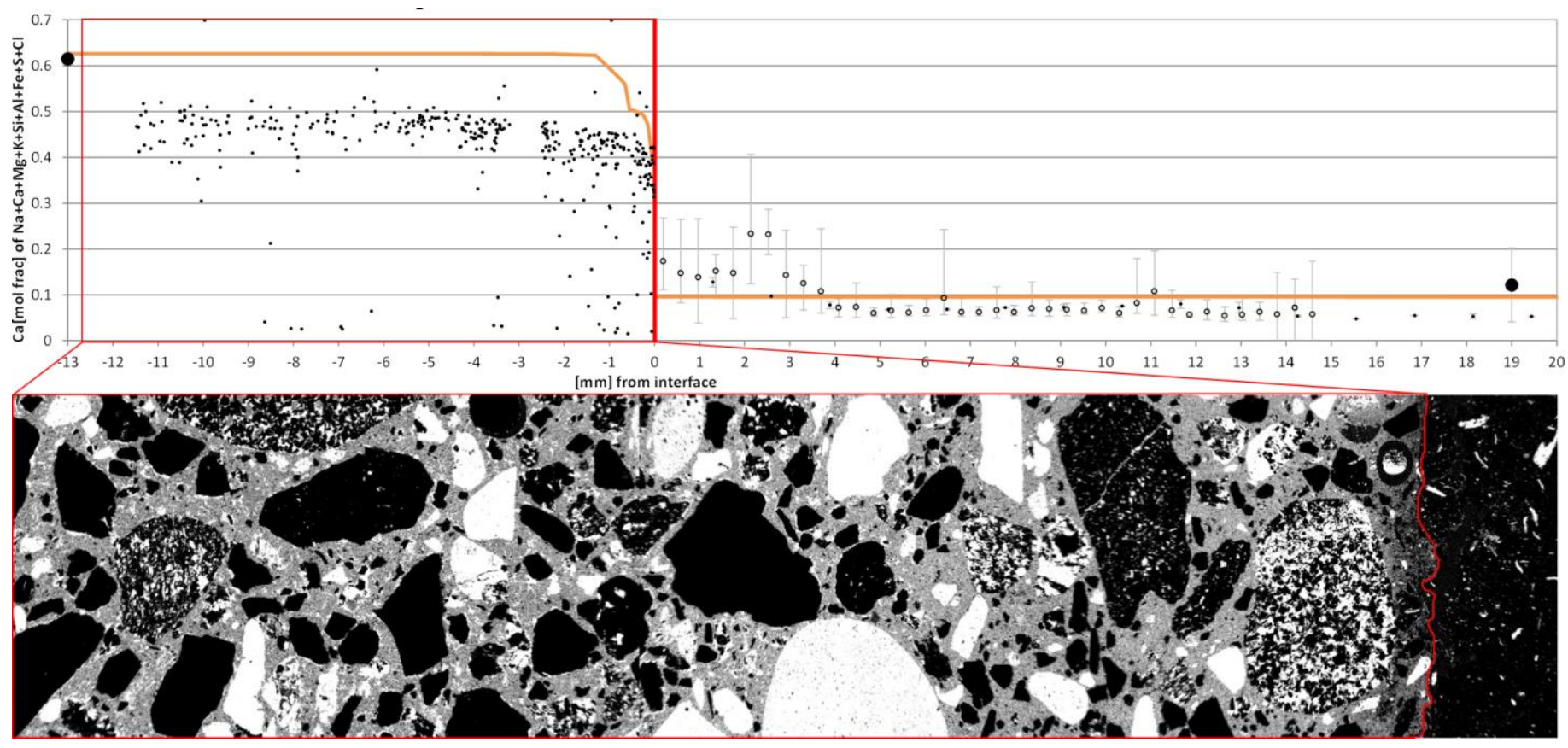

Fig. 8 The upper panel shows Ca mole fractions per total volume at different distances from the interface in the cement matrix (left) and the OPA (right) after $5 \mathrm{y}$ of interaction. Orange line: model output (processing described in chapter 2); small dots: SEM EDX point measurements in the cement matrix; open circles and small dots on the OPA side: average SEM EDX area measurements within layers parallel to the interface with bars showing the variability parallel to the interface; large dot on the left-hand boundary: calculated from cement specifications; large dot on the right: calculated from reference data of shaly OPA with bars indicating the inhomogeneity of the facies. Lower panel: the qualitative SEM EDX Ca map indicates high $\mathrm{Ca}$ in white, low $\mathrm{Ca}$ in black. The area framed in red corresponds with the red framed rectangle in the graph.

The EDX sulphur (S) spot measurements in the cement scatter strongly which is in agreement with the patchy appearance of the cement matrix in the $S$ map (Fig. 9). The $S$ map shows a layer of brighter patches somewhat detached from the interface in qualitative agreement with the model (orange line). In this layer, ettringite together with an increased porosity is predicted (Fig. 6).

The model predicts a S depletion in the OPA within a zone of approximately $1.5 \mathrm{~mm}$ from the interface, caused by a lower pyrite content. In this zone, pyrite was oxidised by oxygen entering from the cement, resulting in the precipitation of iron (hydro)oxides and the release of sulphate which subsequently diffuses into the cement. The heterogeneous distribution of pyrite in the OPA relative to the scale of investigation makes it impossible to accurately measure this process. However, Raman spectroscopy confirms the existence of a hematite layer on pyrite grain surfaces close to the interface, supporting the occurrence of this local oxidation process. 


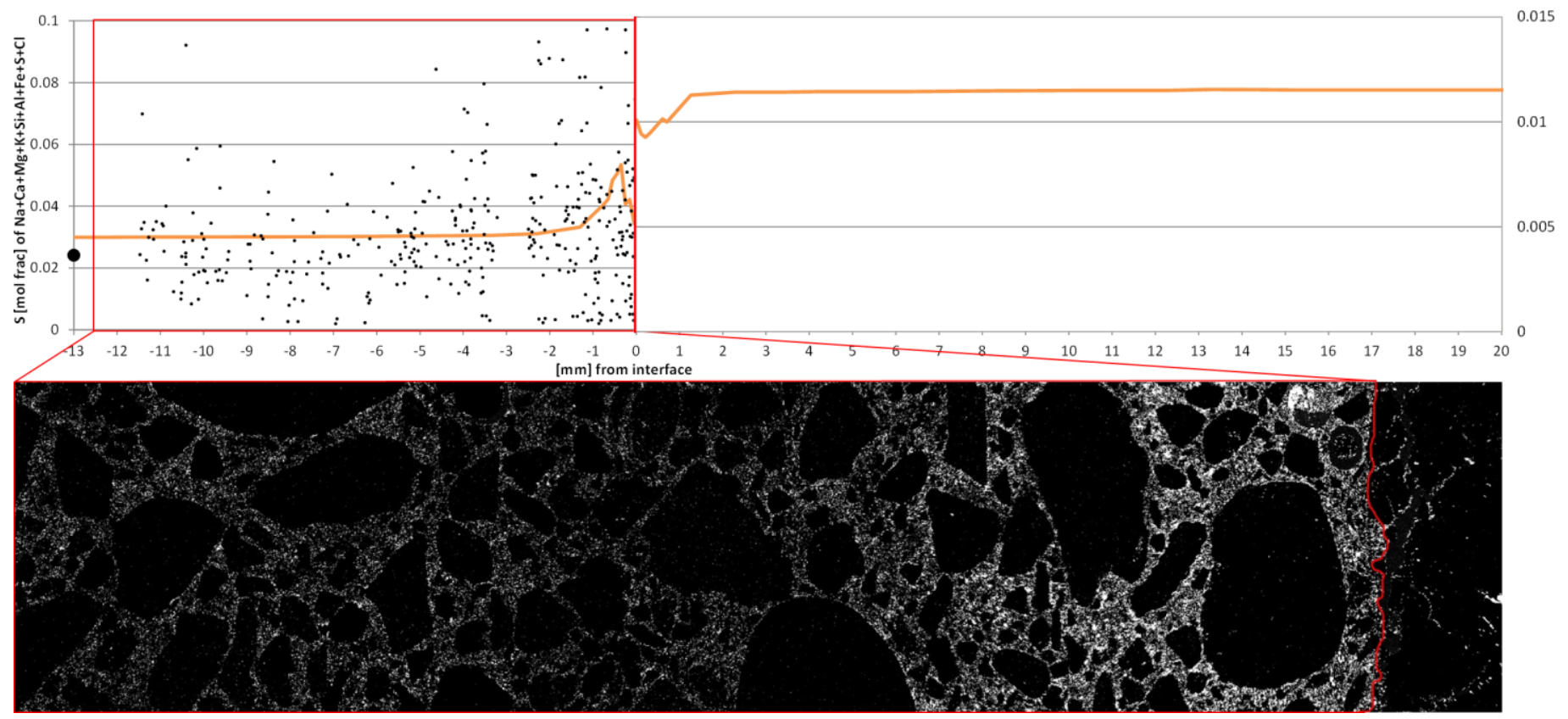

Fig. 9 The upper panel shows S mole fractions per total volume at different distances from the interface in the cement matrix (left) and the OPA (right) after $5 \mathrm{y}$ of interaction. Orange line: model output (processing described in chapter 2); small dots: SEM EDX point measurements in the cement matrix; SEM EDX area measurements in OPA are not shown because they scatter extremely at this scale due to inhomogeneous distribution of pyrite nests; large dot on the left-hand boundary: calculated from cement specifications. Lower panel: the qualitative SEM EDX S map indicates high $S$ in white, low $S$ in black. The area encircled in red corresponds to the red rectangle in the graph.

Low-pH cements show a significant Mg enrichment at interfaces with OPA which extends into the clay (Jenni et al., 2014). The present model predicts a similar Mg enrichment in OPC caused by brucite and increased hydrotalcite (Fig. 6), which has not been confirmed by measurements (Fig. 10) or by Mäder et al. (accepted). However, Jenni et al. (2014) describe the occurrence of distinct Mg hydrate grains at the interface in the same OPC, although with lower $\mathrm{w} / \mathrm{c}$. 


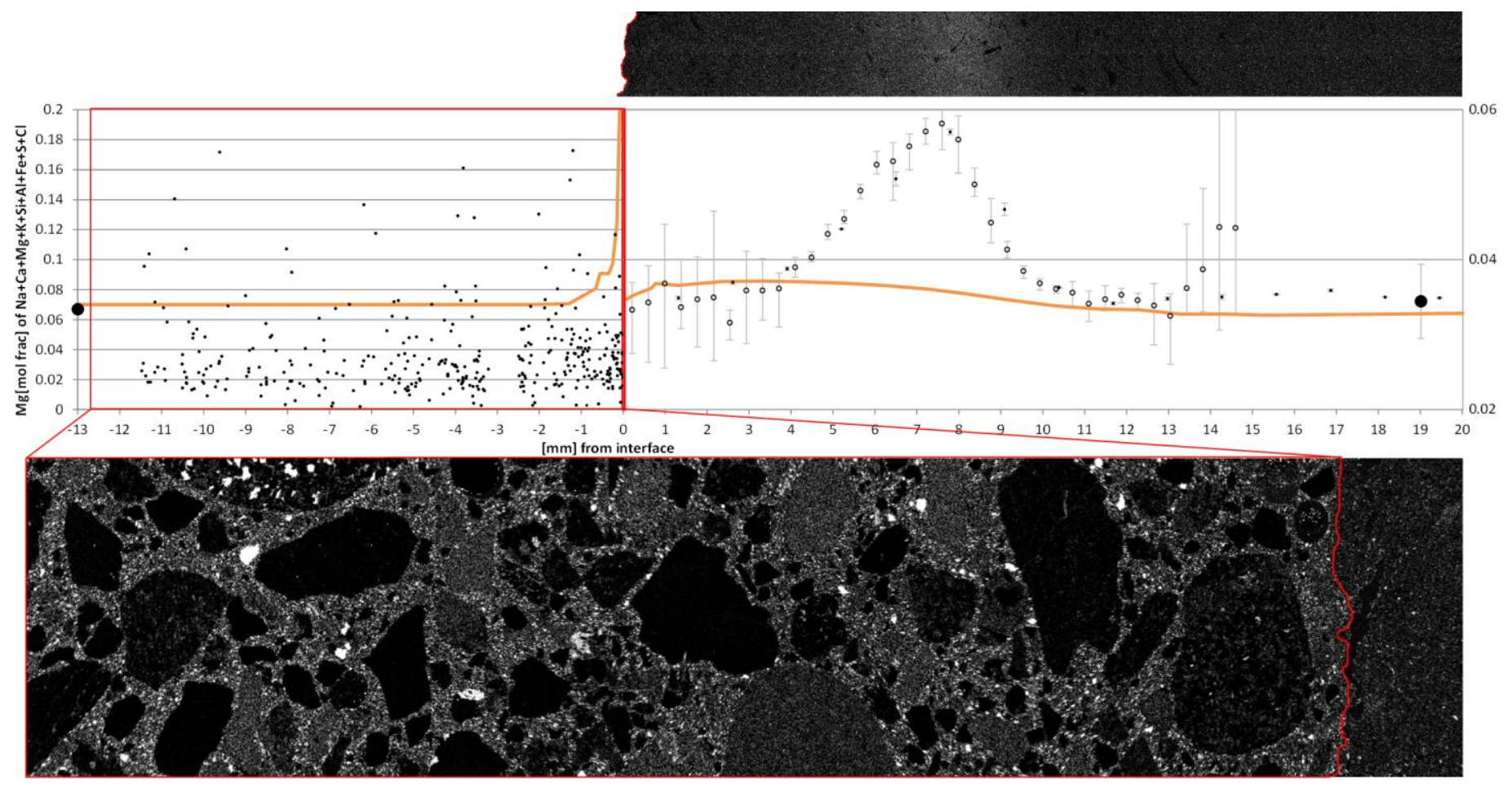

Fig. 10 The upper panel shows Mg mole fractions per total volume at different distances from the interface in the cement matrix (left) and the OPA (right) after $5 \mathrm{y}$ of interaction. Orange line: model output (processing described in chapter 2); small dots on the left: SEM EDX point measurements in the cement matrix; open circles and small dots on the right: average SEM EDX area measurements in Opa in layers parallel to the interface with bars showing the variability parallel to the interface; large dot on the left-hand boundary: calculated from cement specifications; large dot on the right-hand boundary: calculated from reference data of shaly OPA with bars indicating the inhomogeneity of the facies. The qualitative SEM EDX $\mathrm{Mg}$ map (bottom) indicates high $\mathrm{Mg}$ in white, low Mg in black. The area framed in red corresponds with the red framed rectangle in the graph. The qualitative SEM EDX Mg map of OPA quantified in the graph is shown in the top panel.

The Mg-enriched zone in the OPA at 6-8 mm from the interface (Fig. 10) has not been found at any other sampled interface so far (Read et al., 2001; Tinseau et al., 2006; Dauzères et al., 2010; Jenni et al., 2014). The increase in the total $\mathrm{Mg}$ content in this zone is small in absolute terms ( $2 \mathrm{~mol} \%$, close to the EDX sensitivity), but constitutes a strong local maximum, with $\mathrm{Mg}$ contents similar to OPA reference values ( $\sim 3.5 \mathrm{~mol} \%)$ to the left and the right. The simulation (orange line) suggests a similar, but even lower $\mathrm{Mg}$ enrichment related to the formation of hydrotalcite and brucite.

The model predicts most trends observed in the samples well, except the false prediction of Mg hydrates precipitating in OPC close to the OPA. The chemical and mineralogical alterations caused by the interaction between the two materials are relatively small given the compositional differences. Compositional heterogeneities in both the concrete and the OPA and the partly low element contents introduce comparably large measurement errors at the considered spatial scales. In view of these uncertainties, the qualitative agreement between model results and experimental data can be considered as acceptable. On the other hand, the model complexity involving many poorly constrained transport and dissolution kinetics parameters implies also a large uncertainty of the simulation results. In the current modelling approach, no attempt was undertaken to improve the match with experimental data by fitting poorly constrained parameters. Instead, all parameter values were defined based on carefully selected literature data.

\section{Conclusions}

The reactive transport model of a cement-claystone interface presented here considers explicitly the anion-depleted porosity of clays (Donnan porosity) and diffusive transport that occurs therein. Diffusion in the Donnan porosity is important in particular in cases where clogging of the free porosity occurs (chapter 3.3). We examined the interface between a concrete and OPA in which complete porosity clogging was never observed experimentally during $5 \mathrm{y}$ of interaction. Nevertheless, diffusion in the Donnan porosity adds an important diffusive pathway for (mainly) cations in 
addition to that in the free porosity. In previous modelling efforts (De Windt et al., 2008; Marty et al., 2009; Kosakowski and Berner, 2013) it was assumed that transport takes place exclusively within the free porosity.

The model predicts main features at the interface observed after $5 \mathrm{y}$ of interaction and allows for the interpretation of underlying mechanisms:

Cement decalcification at the interface: depletion of portlandite and ettringite. So far, it has been assumed that the local $\mathrm{pH}$ drops below the stability field of these phases due to the buffering effect of the OPA. But the present model suggests that there is no significant $\mathrm{pH}$ drop in the cement at the interface. Nevertheless, portlandite and ettringite formation is restricted, a $\mathrm{Ca}^{++}$gradient builds up and leads to the diffusion of $\mathrm{Ca}++$ into the OPA. Therefore, the depletion of portlandite and ettringite has to be caused by a shortage in $\mathrm{Ca}^{++}$(confirmed by the model results) rather than by a change in $\mathrm{pH}$. Furthermore, the pore water is always slightly oversaturated with respect to calcite on both sides of the interface, whereby the zone of calcite oversaturation penetrates deeper into the OPA over time. After approximately $2 \mathrm{y}$ of interaction, the pore water is in equilibrium with calcite in both the cement and the OPA.

Sulphur maximum in the cement: the model predicts oversaturation with respect to ettringite at the interface within the first weeks followed by a slight undersaturation and attaining equilibrium after approximately $1 \mathrm{y}$. This is consistent with the remaining $S$ that still can be measured in the cement between the $S$ maximum and the interface. If ettringite undersaturation was related to a low $\mathrm{pH}$, no $\mathrm{S}$ phase would be expected here, and total $\mathrm{S}$ would be below EDX detection limit. The weak local $\mathrm{S}$ maximum is caused by the increased availability of $\mathrm{Ca}^{++}$, combined with the diffusion of sulphate from the OPA into the concrete following the oxidation of pyrite in the OPA, leading to ettringite formation. In addition, because portlandite is still absent in this zone, the porosity is relatively high such that the concentration of all elements except $\mathrm{Ca}$ is increased in EDX (remaining elements have to add up to $100 \mathrm{~mol} \%$ ).

Mg maximum in OPA: the shape of the Mg peak observed in Opa at $\sim 7 \mathrm{~mm}$ from the interface was not reproduced by the model, but instead produced a slight, but broad $\mathrm{Mg}$ enrichment from $\sim 1$ to $8 \mathrm{~mm}$. The model predicts mainly hydrotalcite in the OPA close to the interface followed by brucite further away. Precipitation of these minerals follows the high-pH plume penetrating the OPA with time (Fig. 11): just behind the high-pH plume, brucite precipitation is highest, followed by hydrotalcite further away. At the very front, a complex multiphase dissolution/precipitation behaviour can be observed. The dolomite precipitation peak at $1 \mathrm{~d}$ is only present at few selected time steps and most likely a numerical artefact, possibly related to the inhomogeneous grid discretisation (8 cells of $0.1 \mathrm{~mm}$ at the interface, followed by 15 cells of $1 \mathrm{~mm}$, and 2 cells of $100 \mathrm{~mm}$ further into the OPA). 

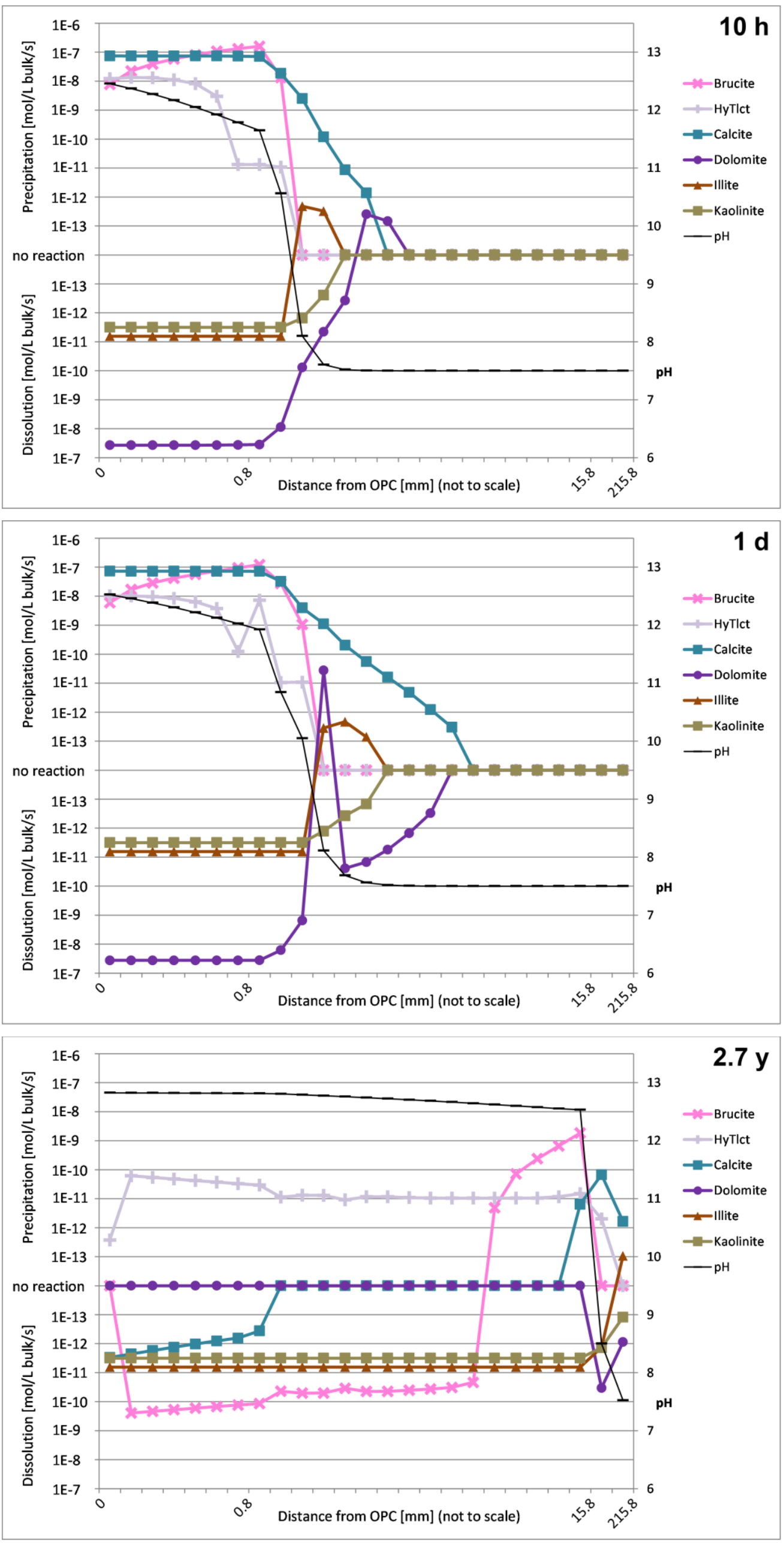
Fig. 11 Reaction rates (modelled with $\mathrm{G}_{\text {Donnan }}=0.006$, corresponding with Fig. 6) in OPA of the main minerals at $10 \mathrm{~h}, 1 \mathrm{~d}$, and $2.7 \mathrm{y}$, and the pH in the free porosity, at different distances from the interface with OPC. Rates below $1 \mathrm{E}-13 \mathrm{~mol} / \mathrm{L}$ bulk/s are plotted as zero (no reaction). The inhomogeneous $x$-axis causes apparent steps in the curves at $0.8 \mathrm{~mm}$ and $15.8 \mathrm{~mm}$.

The higher Mg content of brucite compared to hydrotalcite (on a per volume basis) leads to a lower total Mg content where hydrotalcite dominates ( $\sim 0.8 \mathrm{~mm}$ from interface) and to a $\mathrm{Mg}$ maximum in the brucite area $(\sim 1-7 \mathrm{~mm}$ from interface). The replacement of dolomite with calcite which occurs already at slightly increased pH (Fig. 11) can explain only part of the $\mathrm{Mg}$ enrichment. The other source is the $\mathrm{Mg}$ on the clay exchanger or, in other words, the $\mathrm{Mg}$ concentration in the Donnan porosity. The initial Mg in the Donnan porosity ( 20 eq\% of the CEC) has completely exchanged with $\mathrm{Ca}$ and $\mathrm{K}$ within the high-pH plume entering from the cement (population at $100 \mathrm{~d}$ of interaction in Fig. 12). This exchange is associated with a $\mathrm{Mg}$ decrease in the free porosity, which only provides a $\mathrm{Mg}$ reservoir that is more than 60 times smaller (in terms of total Mg mass). On the other hand, the Mg decrease in the Donnan porosity has only a minor influence on total $\mathrm{Mg}$ measured to the left and right of the $\mathrm{Mg}$ peak, and is therefore not clearly visible in Fig. 10. Because the hydrotalcite and brucite precipitation can be related to the high-pH front moving into the OPA, the discrepancy between the measured and modelled shape of the Mg peak might be due to the chosen dissolution kinetics and transport parameters. Nevertheless, the mechanisms revealed by the simulation might serve as an explanation of the observed Mg peak.

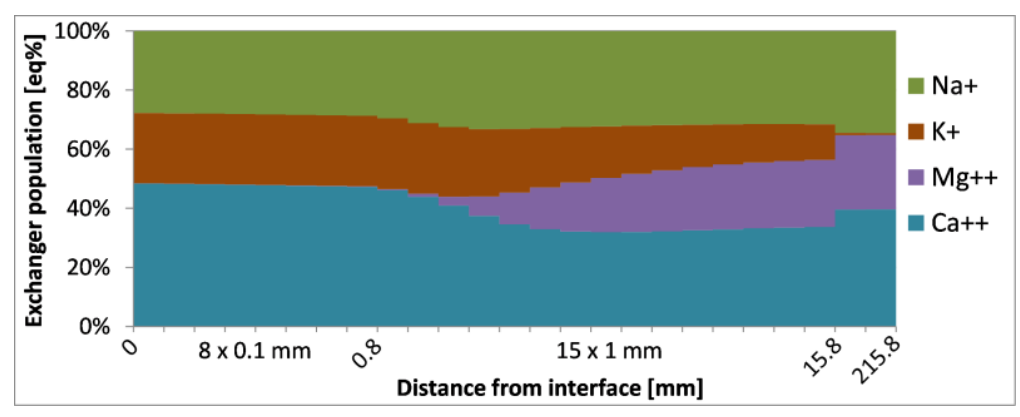

Fig. 12 Main cation occupancy of the clay exchanger in the OPA, equal to the relative charge distribution of the main cations in the Donnan porosity at $100 \mathrm{~d}$ of interaction.

No carbonation layer in the cement: in contrast to interfaces with other cements, no distinct carbonation layer was observed by light microscopy in this study. Consistent with this observation, the model predicts cement-internal dolomite dissolution as the only source of carbon species, leading to uniform calcite formation throughout the entire cement domain. Right after the start of diffusive exchange across the interface, the high-pH plume enters the OPA, dolomite disappears from the interfacial region, $\mathrm{HCO}_{3}{ }^{-}$concentrations on both sides of the interface equilibrate and are both controlled by calcite. Carbonation has been associated with pore clogging at the interface in other cement-clay constellations (Jenni et al., 2014).

Modelling the OPC-OPA interface with the dual-porosity approach predicts the general observations well. Based on the mechanisms revealed by the model, the following overall conclusions can be drawn. Possible implications of concrete being used for tunnel stabilisation in a deep geological waste repository are also indicated.

- Severe reactions occur at the interface during the main hydration period of the cement $(<1 \mathrm{y})$. Therefore, modelling of cement-clay interfaces must start with the fresh concrete in order to understand the features observed in a real sample and to understand the underlying mechanisms. This also means that the initial conditions are crucial: the clay surface in a repository is expected to be slightly desaturated, oxidised and cracked before the concrete is applied. This would cause advection, gas flow, shortage of cement hydration water, increased sulphate content in the claystone porewater or heterogeneous precipitation to occur upon juxtaposition of the two materials. The uncertainties of the initial conditions add to the uncertainty of the reactive transport model. Incorporating all of the above mentioned processes into a reactive transport model 
of a repository is extremely demanding. Luckily, for the $\mathrm{Cl}$ experiment it can be assumed that the clay around the borehole was comparably undisturbed because of the relatively short time in contact with air.

- The main hydration period of the cement falls into the operational phase of the repository, where compressive strength of the concrete is of importance. After $5 \mathrm{y}$ the model predicts a porosity increase of around $4 \mathrm{vol} \%$ within $1 \mathrm{~mm}$ of the concrete at the interface which will have only a marginal impact on total strength.

- The model predicts only minor clogging of the free porosity within $5 \mathrm{y}$ and indicates that mineral precipitation extends into the clay rather than being localised at the interface, thereby reducing the impact on porosity and transport. The transport pathway along the free porosity remains open. Also, possible advective transport can continue, e.g. hydration of bentonite across a concrete liner is not stopped due to a skin effect. On the other hand, processes in OPA triggered by the cement can continue over much longer times than the $5 \mathrm{y}$ period of this study.

- A high-pH plume enters the OPA: after $5 \mathrm{y}$ of interaction the $\mathrm{pH}$ within a $16 \mathrm{~mm}$ thick zone in the OPA layer exceeds 12.5. Accessory dolomite has dissolved and the main clay phases become unstable. Due to the slow kinetics the dissolution of clay phases will impact on the system only in the long run. Mass-balance calculations can be used to roughly estimate the volume of OPA per volume of cement that is affected by chemical reactions (and hence the volume that may undergo a change in physico-chemical properties, including its retention behaviour or swelling pressure). Especially low-pH cements show more severe and more localised reactions, hence pore clogging is expected to be more significant. Mineral precipitation on the cement side of the interface can then possibly stop the diffusive exchange and chemical interactions. In contrast, if complete clogging occurs on the OPA side, the Donnan porosity is expected to remain open, allowing for a limited transport of anions but for fast exchange of cations across the interface (chapter 3.3).

- The model prediction is very sensitive to parameters with large uncertainties (geometric factors for the calculation of diffusive transport, dissolution kinetics/ surface areas, certain thermodynamic data). For example, different diffusion data from OPA lead to contradictory geometric factors (Table 2). The accuracy of the M-S-H thermodynamic data used in this study is currently under discussion. However, the absence of M$\mathrm{S}-\mathrm{H}$ phases from the modelled alteration assemblage agrees with experimental observations from OPC samples.

- The evolution at the interface strongly depends on the type of cement. The application of the dual porosity model approach to a low-pH concrete - OPA interface will probably consolidate the importance of the Donnan porosity, provided that a model can be constructed that is constrained by reliable data and observations, which are different from the ones presented here.

\section{Acknowledgements}

The analytical results presented here rely on samples carefully crafted by the rock preparation team of the Institute of Geological Sciences, University of Bern. The Mt Terri Cl Project is funded by ANDRA, CRIEPI, FANC, Nagra, Obayashi, and SCK.CEN. The scientific and technical team operating the Mont Terri facility (Swisstopo) is acknowledged for field support. The demanding drilling was professionally performed by Schützeichel $\mathrm{GmbH} \&$ Co.KG.

\section{References}

Adler, M., 2001. Interaction of claystone and hyperalkaline solutions at $30^{\circ} \mathrm{C}$ : A combined experimental and modeling study. University of Bern, Switzerland, Bern. 
Alt-Epping, P., Tournassat, C., Rasouli, P., Steefel, C.I., Mayer, K.U., Jenni, A., Mäder, U., Sengor, S.S., Fernández, R., 2014. Benchmark reactive transport simulations of a column experiment in compacted bentonite with multispecies diffusion and explicit treatment of electrostatic effects. Computational Geosciences, 1-16.

Appelo, J.A.C., Wersin, P., 2007. Multicomponent diffusion modeling in clay systems with application to the diffusion of tritium, iodide, and sodium in Opalinus Clay. Environmental Science \& Technology 41, 5002-5007.

Babushkin, V.I., Matveyev, G.M., Mchedlov-Petrossyan, O.P., 1985. Thermodynamics of silicates. Springer, Berlin.

Berner, U., Kulik, D.A., Kosakowski, G., 2013. Geochemical impact of a low-pH cement liner on the near field of a repository for spent fuel and high-level radioactive waste. Physics and Chemistry of the Earth 64, 46-56.

Birgersson, M., Karnland, O., 2009. Ion equilibrium between montmorillonite interlayer space and an external solutionconsequences for diffusional transport. Geochimica et Cosmochimica Acta 73, 1908-1923.

Brew, D.M.R., Glasser, F.P., 2005. The magnesia-silica gel phase in slag cements: Alkali (K, Cs) sorption potential of synthetic gels. Cement and Concrete Research 35, 77-83.

Chagneau, A., Tournassat, C., Steefel, C.I., Bourg, I.C., Gaboreau, S., Esteve, I., Kupcik, T., Claret, F., Schaefer, T., 2015. Complete restriction of ${ }^{36} \mathrm{Cl}$ diffusion by celestite precipitation in densely compacted illite. Environmental Science \& Technology Letters 2, 139-143.

Dauzères, A., Achiedo, G., Nied, D., Bernard, E., Alahrache, S., Lothenbach, B., 2016. Magnesium perturbation in low-pH concretes placed in clayey environment-solid characterizations and modeling. Cement and Concrete Research 79, 137-150.

Dauzères, A., Le Bescop, P., Sardini, P., Coumes, C.C.D., 2010. Physico-chemical investigation of clayey/cementbased materials interaction in the context of geological waste disposal: Experimental approach and results. Cement and Concrete Research 40, 1327-1340.

De Windt, L., Marsal, F., Tinseau, E., Pellegrini, D., 2008. Reactive transport modeling of geochemical interactions at a concrete/argillite interface, Tournemire site (France). Physics and Chemistry of the Earth 33, S295-S305.

Delagrave, A., Marchand, J., Samson, E., 1996. Prediction of diffusion coefficients in cement-based materials on the basis of migration experiments. Cement and Concrete Research 26, 1831-1842.

Erdoğdu, Ş., Kondratova, I.L., Bremner, T.W., 2004. Determination of chloride diffusion coefficient of concrete using open-circuit potential measurements. Cement and Concrete Research 34, 603-609.

Flury, M., Gimmi, T., 2002. Solute diffusion, in: Dane, J.H., Topp, G.C. (Eds.), Methods of Soil Analysis, Part 4: Physical Methods. Soil Science Society of America, Inc., Madison, Wisconsin, USA.

Gimmi, T., Kosakowski, G., 2011. How mobile are sorbed cations in clays and clay rocks? Environmental Science and Technology 45, 1443-1449.

Gonzalez Sanchez, F., Gimmi, T., Juranyi, F., Van Loon, L., Diamond, L.W., 2009. Linking the diffusion of water in compacted clays at two different time scales: Tracer through-diffusion and quasielastic neutron scattering. Environmental Science \& Technology 43, 3487-3493.

Gonzalez Sanchez, F., Juranyi, F., Gimmi, T., Van Loon, L., Unruh, T., Diamond, L.W., 2008. Translational diffusion of water and its dependence on temperature in charged and uncharged clays: A neutron scattering study. Journal of Chemical Physics 129.

Hedstrom, M., Karnland, O., 2011. Ca/Na selectivity coefficients from the Poisson-Boltzmann theory. Physics and Chemistry of the Earth 36, 1559-1563. 
Hummel, W., Berner, U., Curti, E., Pearson, F.J., Thoenen, T., 2002. Nagra/PSI chemical thermodynamic data base 01/01. Radiochimica Acta 90, 805-813.

Jenni, A., Mäder, U., Lerouge, C., Gaboreau, S., Schwyn, B., 2014. In situ interaction between different concretes and Opalinus Clay. Physics and Chemistry of the Earth, Parts A/B/C 70-71, 71-83.

Jenni, A., Mäder, U., Wieland, E., Lerouge, C., Gaboreau, S., 2015. Concrete-clay interaction: Give-and-take without a loser?, in: ONDRAF (Ed.), 6th Meeting on Clays in Natural and Engineered Barrier for Radioactive Waste Confinement, Brussels, Belgium.

Kosakowski, G., Berner, U., 2013. The evolution of clay rock/cement interfaces in a cementitious repository for lowand intermediate level radioactive waste. Physics and Chemistry of the Earth 64, 65-86.

Kulik, D.A., 2011. Improving the structural consistency of C-S-H solid solution thermodynamic models. Cement and Concrete Research 41, 477-495.

L'Hôpital, E., Lothenbach, B., Scrivener, K., Kulik, D.A., 2016. Alkali uptake in calcium alumina silicate hydrate (C-A-SH). Cement and Concrete Research 85, 122-136.

Lasaga, A.C., 1981. Transition state theory. Reviews in Mineralogy and Geochemistry 8, 135-168.

Lasaga, A.C., 1984. Chemical-kinetics of water-rock interactions. Journal of Geophysical Research 89, 4009-4025.

Lichtner, P.C., 2007. Flotran user's manual version 2.0: LA-CC 02-036, Los Alamos National Laboratory, Los Alamos, NM, USA.

Lothenbach, B., 2013. Hydration of blended cements, in: Bart, F., Cau-di-Coumes, C., Frizon, F., Lorente, S. (Eds.), Cement-Based Materials for Nuclear Waste Storage. Springer, New York, pp. 33-41.

Lothenbach, B., Wieland, E., 2006. A thermodynamic approach to the hydration of sulphate-resisting Portland cement. Waste Management 26, 706-719.

Lothenbach, B., Winnefeld, F., 2006. Thermodynamic modelling of the hydration of Portland cement. Cement and Concrete Research 36, 209-226.

Mäder, U., 2009. Reference pore water for the Opalinus Clay and "Brown Dogger" for the provisional safety-analysis in the framework of the sectorial plan - interim results (SGT-ZE), NAB 09-14, Nagra, Wettingen, Switzerland.

Mäder, U., Jenni, A., Lerouge, C., Gaboreau, S., Miyoshi, S., Kimura, Y., Cloet, V., Fukaya, M., Claret, F., Otake, T., Shibata, M., Lothenbach, B., accepted. 5-year chemico-physical evolution of concrete-claystone interfaces. Swiss Journal of Geosciences.

Marty, N.C.M., Tournassat, C., Burnol, A., Giffaut, E., Gaucher, E.C., 2009. Influence of reaction kinetics and mesh refinement on the numerical modelling of concrete/clay interactions. Journal of Hydrology 364, 58-72.

Matschei, T., Lothenbach, B., Glasser, F.P., 2007. Thermodynamic properties of Portland cement hydrates in the system $\mathrm{CaO}-\mathrm{Al}_{2} \mathrm{O}_{3}-\mathrm{SiO}_{2}-\mathrm{Ca}_{5} \mathrm{O}_{4}-\mathrm{CaCO}_{3}-\mathrm{H}_{2} \mathrm{O}$. Cement and Concrete Research 37, 1379-1410.

Mazurek, M., 2011. Aufbau und Auswertung der Gesteinsparameter-Datenbank für Opalinuston, den 'Braunen Dogger', Effinger Schichten und Mergel-Formationen des Helvetikums, NAB 11-020, Nagra, Wettingen, Switzerland.

Melkior, T., Mourzagh, D., Yahiaoui, S., Thoby, D., Alberto, J.C., Brouard, C., Michau, N., 2004. Diffusion of an alkaline fluid through clayey barriers and its effect on the diffusion properties of some chemical species. Applied Clay Science 26, 99-107. 
Moeschner, G., Lothenbach, B., Rose, J., Ulrich, A., Figi, R., Kretzschmar, R., 2008. Solubility of Fe-ettringite $\left(\mathrm{Ca}_{6}\left[\mathrm{Fe}(\mathrm{OH})_{6}\right]_{2}\left(\mathrm{SO}_{4}\right)_{3} 26 \mathrm{H}_{2} \mathrm{O}\right)$. Geochimica et Cosmochimica Acta 72, 1-18.

Moeschner, G., Lothenbach, B., Winnefeld, F., Ulrich, A., Figi, R., Kretzschmar, R., 2009. Solid solution between Alettringite and Fe-ettringite $\left(\mathrm{Ca}_{6}\left[\mathrm{Al}_{1-x} \mathrm{Fe}_{x}(\mathrm{OH})_{6}\right]_{2}\left(\mathrm{SO}_{4}\right)_{3} 26 \mathrm{H}_{2} \mathrm{O}\right)$. Cement and Concrete Research 39, 482-489.

Nestle, N., Galvosas, P., Kärger, J., 2007. Liquid-phase self-diffusion in hydrating cement pastes — results from nmr studies and perspectives for further research. Cement and Concrete Research 37, 398-413.

Nied, D., Enemark-Rasmussen, K., L'Hopital, E., Skibsted, J., Lothenbach, B., 2016. Properties of magnesium silicate hydrates (M-S-H). Cement and Concrete Research 79, 323-332.

Palandri, J.L., Kharaka, Y.K., 2004. A compilation of rate parameters of water-mineral interaction kinetics for application to geochemical modeling, U.S. Geological Survey, Washington, USA.

Parrot, L.J., Killoh, D.C., 1984. Prediction of cement hydration, British Ceramic Society congress, pp. 41-53.

Pearson, F.J., Arcos, D., Bath, A., Boisson, J.-Y., Fernández, A.M., Gäbler, H.-E., Gaucher, E., Gautschi, A., Griffault, L., Hernán, P., Waber, H.N., 2003. Mont Terri Project - geochemistry of water in the Opalinus Clay formation at the Mont Terri rock laboratory, 5, BWG, Bern.

Pearson, F.J., Tournassat, C., Gaucher, E.C., 2011. Biogeochemical processes in a clay formation in situ experiment: Part E - equilibrium controls on chemistry of pore water from the Opalinus Clay, Mont Terri underground research laboratory, Switzerland. Applied Geochemistry 26, 990-1008.

Read, D., Glasser, F.P., Ayora, C., Guardiola, M.T., Sneyers, A., 2001. Mineralogical and microstructural changes accompanying the interaction of Boom Clay with ordinary Portland cement. Advances in Cement Research 13, 175183.

Savage, D., Soler, J.M., Yamaguchi, K., Walker, C., Honda, A., Inagaki, M., Watson, C., Wilson, J., Benbow, S., Gaus, I., Rueedi, J., 2011. A comparative study of the modelling of cement hydration and cement-rock laboratory experiments. Applied Geochemistry 26, 1138-1152.

Schmidt, T., Lothenbach, B., Romer, M., Scrivener, K., Rentsch, D., Figi, R., 2008. A thermodynamic and experimental study of the conditions of thaumasite formation. Cement and Concrete Research 38, 337-349.

Shafizadeh, A., Gimmi, T., Van Loon, L., Kaestner, A., Lehmann, E., Maeder, U.K., Churakov, S.V., 2015. Quantification of water content across a cement-clay interface using high resolution neutron radiography. Physics Procedia 69, 516-523.

Steefel, C.I., 2009. Crunchflow: Software for modeling multicomponent reactive flow and transport. http://www.csteefel.com, Berkley, USA.

Taylor, H.F.W., 1997. Cement chemistry, second ed. Thomas Telford Publishing, London.

Tinseau, E., Bartier, D., Hassouta, L., Devol-Brown, I., Stammose, D., 2006. Mineralogical characterization of the Tournemire argillite after in situ interaction with concretes. Waste Management 26, 789-800.

Tournassat, C., Appelo, C.A.J., 2011. Modelling approaches for anion-exclusion in compacted Na-bentonite. Geochimica et Cosmochimica Acta 75, 3698-3710.

Tournassat, C., Steefel, C.I., 2015. Ionic transport in nano-porous clays with consideration of electrostatic effects. Reviews in Mineralogy and Geochemistry 80, 287-329.

Van Loon, L.R., Soler, J.M., Bradbury, M.H., 2003. Diffusion of $\mathrm{HTO},{ }^{36} \mathrm{Cl}^{-}$and ${ }^{125} \mathrm{I}^{-}$in Opalinus Clay samples from Mont Terri: Effect of confining pressure. Journal of Contaminant Hydrology 61, 73-83. 
Van Loon, L.R., Wersin, P., Soler, J.M., Eikenberg, J., Gimmi, T., Hernán, P., Dewonck, S., Savoye, S., 2004. In-situ diffusion of $\mathrm{HTO},{ }^{22} \mathrm{Na}^{+}, \mathrm{Cs}^{+}$and $\mathrm{I}^{-}$in Opalinus Clay at the Mont Terri underground rock laboratory. Radiochimica Acta 92, 757.

Walker, C.S., Savage, D., Tyrer, M., Ragnarsdottir, K.V., 2007. Non-ideal solid solution aqueous solution modeling of synthetic calcium silicate hydrate. Cement and Concrete Research 37, 502-511.

Wersin, P., Jenni, A., Mäder, U.K., 2015. Interaction of corroding iron with bentonite in the ABM1 experiment at Äspö, Sweden: A microscopic approach. Clays and Clay Minerals 63, 51-68. 